Luis Pancorbo e Inés Martín Robles

\section{Linajes férreos}

\section{Uso tipológico de precedentes ferroviarios en Albert Kahn}

Palabras clave: Albert Kahn, arquitectura industrial, arquitectura ferroviaria, puentes metálicos ferrocarril, Fordismo, naves de montaje, hangares.

Los edificios industriales de la primera época de Kahn iniciaron un proceso sinérgico con los procesos de montaje, dependiendo cada vez más de la producción en cadena fordista, la cual puede homologarse, en su motricidad lineal, a la de un tren. Así, se llega a mostrar que las numerosas naves de montaje de vehículos para Ford o Packard son edificios de producción industrial y a la vez terminales de carga y descarga ferroviaria. Existió por tanto un interesante trasvase de elementos tipológicos de las construcciones ferroviarias a la arquitectura industrial de Kahn, lo cual se analiza a través de ejemplos característicos como las terminales, las freighthouses, las trainsheds, los depots o las enginehouses. El otro gran tipo constructivo de claro linaje ferroviario fueron los puentes metálicos norteamericanos, que a su vez fueron asimilados en las grandes estructuras de naves y hangares. Con ellos se aportaron soluciones a problemas de luces hasta entonces desconocidas, sugiriéndose un papel destacado, tanto aqui como en otros casos, en el empleo de voladizos.

\section{Introducción. La tradición inevitable}

a figura de Albert Kahn siempre ha L sido portadora de una dualidad intrínseca y contradictoria. Esta dualidad es la que marca normalmente una infranqueable línea divisoria entre la parte industrial y no industrial de su obra. Según el punto de vista adoptado por el investigador, se puede considerar a Kahn como un arquitecto reaccionario, instalado en una cómoda posición acrítica respecto a la arquitectura académica. También si se enfoca desde su arquitectura industrial, Kahn puede ser visto como un radical innovador precursor del funcionalismo y la racionalidad de la vanguardia arquitectónica moderna.

Es obvio también que Albert Kahn, a pesar de haber firmado algunos de los edificios más influyentes para la arquitectura moderna, no ocupa un lugar principal dentro del "panteón" moderno. Las razones de este lugar secundario, se deben buscar en la dificultad para los historiadores o ideólogos de la arquitectura de usar la figura de Kahn como representante de una categoría arquitectónica. Albert Kahn ofrece tal rango de influencias y conexiones dentro de su extensísima obra que, es imposible clasificarlo dentro de una categoria estanca: arquitecto Beaux Arts, representante en Detroit del Chicago Commercial Style, arquitecto moderno, funcionalista radical, autor anónimo de obras ingenieriles, podrian ser algunas de las etiquetas que se le podrian adjudicar, pero ninguna sería capaz de explicarlo en su totalidad. Es quizás esta incapacidad para su clara adscripción, lo que le haga aparecer como un arquitecto marginal en todas ellas y le expulse efectivamente del pódium ocupado por arquitectos más fácilmente clasificables.

El papel de Kahn que tratamos de rescatar en esta investigación es precisamente el de ser un conector, una suerte de correa de transmisión interdisciplinar entre distintas tradiciones. Así ocurre que su principal valor es a la vez el mayor inconveniente para ser reconocido, y se basa en su extraordinariamente compleja y matizada navegación en el espacio de umbral entre diferentes tradiciones.

En este sentido, el caso de Kahn recuerda al de Oliver Evans, el inventor en 1783 del molino mecánico (figura 1), el primer precedente conocido de la línea de montaje, inventado incluso antes de que la industria americana existiera (Giedion 1970: 79-86). Evans ensambló numerosas tecnologias ya existentes para crear algo nuevo y revolucionario. Su invención sería adoptada masivamente y supuso un extraordinario avance técnico inmediatamente imitado. Pero esta iniciativa no deparó dinero ni reconocimiento a Adams. Los nuevos usuarios del invento recurrieron al recién nacido Congreso Americano para intentar que se les liberase del pago de la patente de Evans. El Congreso nombró al arquitecto Thomas Jefferson experto evaluador. Jefferson no analizó el invento como un todo, sino como un agregado de partes. Estas partes fueron estudiadas por separado, estableciendo que cada una de ellas ya había sido inventada
Architecture. School of Architecture. University of Virginia. 


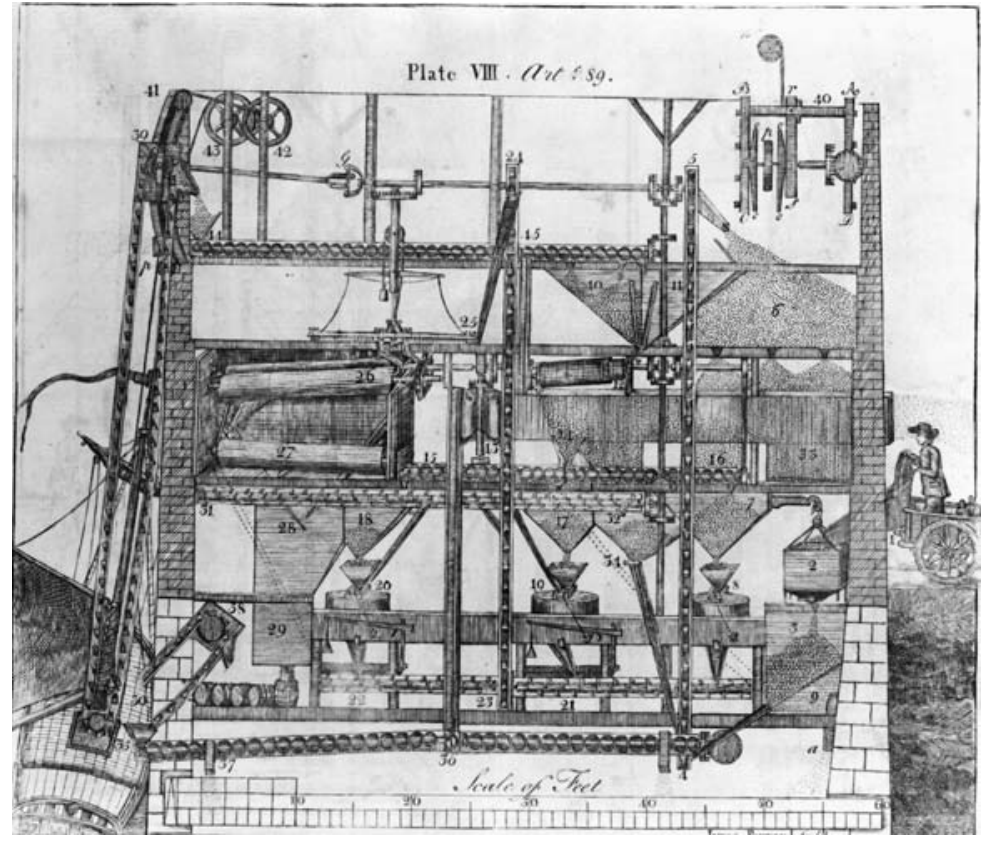

Figura 1. Oliver Evans, Molino automático de grano. (Giedion 1970) con anterioridad: el elevador de grano era una antigua rueda egipcia, el tornillo continuo fue inventado por Arquímedes y ya había sido utilizado en el Renacimiento por Ramelli para transportar verticalmente líquidos. Evans solo cambió el eje a una posición horizontal y lo hizo transportar sólidos. Jefferson hizo un informe contrario a la patente de Evans, que quedó sin efecto, y Evans, como Kahn, quedó sin reconocimiento y, al contrario que Kahn, sin ningún beneficio económico. En ambos casos el inventor y el arquitecto producen algo realmente innovador, de importancia vital para el desarrollo de sus disciplinas. En ambos casos quedan sin reconocimiento precisamente por su labor de transmisión de elementos tradicionales y su nueva inserción y adaptación creando una nueva sintesis por medio del montaje en una tradición distinta.

Consideramos que Kahn es el mediador principal entre la tradición clásica arquitectónica y la ingenieria. Es el transmisor efectivo, no teórico, de las herramientas y procedimientos de la ingenieria a la arquitectura, y el principal e involuntario transmisor también de estas herramientas a la arquitectura moderna a través de la influencia de su obra industrial. En este texto se intenta desgranar la relación de Kahn con las tradiciones de las que él mismo procede. Para ello definiremos primero brevemente el concepto de tradición que estamos usando y luego estableceremos cuál es la tradición a la que Albert Kahn pertenece y cuáles son los modos de transmisión y mutación de esta tradición.
En la teoría de la tradición de MacIntyre (1981: 1988) aparecen dos temas: la concepción dinámica de la tradición, que necesita de la confrontación y el debate para progresar; y la consideración de la tradición como un "depósito de racionalidad" (con el corolario de que no existe racionalidad fuera de la tradición). El análisis de estas dos características fundamentales del concepto de tradición en el autor escocés, nos guía a la explicación de las condiciones necesarias para conseguir el diálogo entre varias tradiciones; en este caso, la tradición arquitectónica moderna y la tradición de la ingeniería industrial americana.

Para MacIntyre, oponiéndose al tradicionalismo conservador, las tradiciones son entes en perpetuo cambio (pueden progresar pero también degenerar), son realidades dinámicas que dependen del progreso en la investigación y de la contradicción:

"Todo razonamiento tiene lugar dentro del contexto de algún modo tradicional de pensar, trascendiendo las limitaciones de lo que en esa tradición se ha razonado por medio de la crítica y la invención (...) Las tradiciones, cuando están vivas, incorporan continuidades de conflicto", su continuidad y salud dependen de "el rechazo, la enmienda y reformulación de creencias, la revalorización de las autoridades, la reinterpretación de los textos, la emergencia de nuevas formas de autoridad y la producción de nuevos textos". (De la Torre 2001: 105)

Así, la confrontación entre arquitectura moderna y de los estilos clásicos, se debería englobar dentro de una crisis epistemológica general de una tradición, es decir, en "la disolución de las certezas fundadas o establecidas históricamente" (De la Torre 2001: 115). Esta crisis es debida tanto a conflictos internos (ya que el Movimiento Moderno rechazaba la mayor parte de los acuerdos fundamentales de la arquitectura académica), como externos (con la importación de un nuevo tipo de racionalidad desde una tradición perteneciente a otro campo disciplinar: la ingeniería y la industria).

La posición de Kahn aparece como la del mediador entre tradiciones, la de un articulador que supo ver que la crisis epistemológica no se iba a resolver con el predominio total de la tradición recién llegada y la destrucción de la anterior, sino con la inclusión del Movimiento Moderno, dentro de la tradición global aunque con un papel predominante. 


\section{Albert Kahn y la Ingenieria ferroviaria americana como tradición}

Enunciamos aquí la hipótesis de trabajo principal del artículo: la tradición en la que se debe inscribir a Albert Kahn y de donde proceden sus obras industriales, no es la tradición de la ingeniería fabril americana donde lo sitúan autores como Banham (1986), sino la tradición de la ingeniería ferroviaria americana. Tratando de repasar cuáles son los rasgos característicos de los edificios de Kahn que nos hacen formular esta hipótesis sobre el uso de tipos ferroviarios en la génesis de su arquitectura industrial, aparecen dos consideraciones principales.

Los edificios industriales de la primera época de Kahn, en la que se produce la deriva desde el proyecto de arquitectura hasta el proyecto de un objeto técnico puro, provienen directamente de las condiciones de la producción que acogen en su interior. Son edificios que entran en un proceso sinérgico con la cadena de montaje, pasando a formar la parte espacial y material de una máquina global compuesta por maquinas, trabajadores y arquitectura. Así, son edificios que dependen cada vez más de la forma que adopta la producción en cadena fordista. Esta forma de producción es en todo caso, homologable en su motricidad lineal, a la de un tren. Una cadena de montaje, bien podría denominarse "tren de montaje" sin perder un

Figura 2. Linea de desmontaje de cerdos. (Giedion 1970)

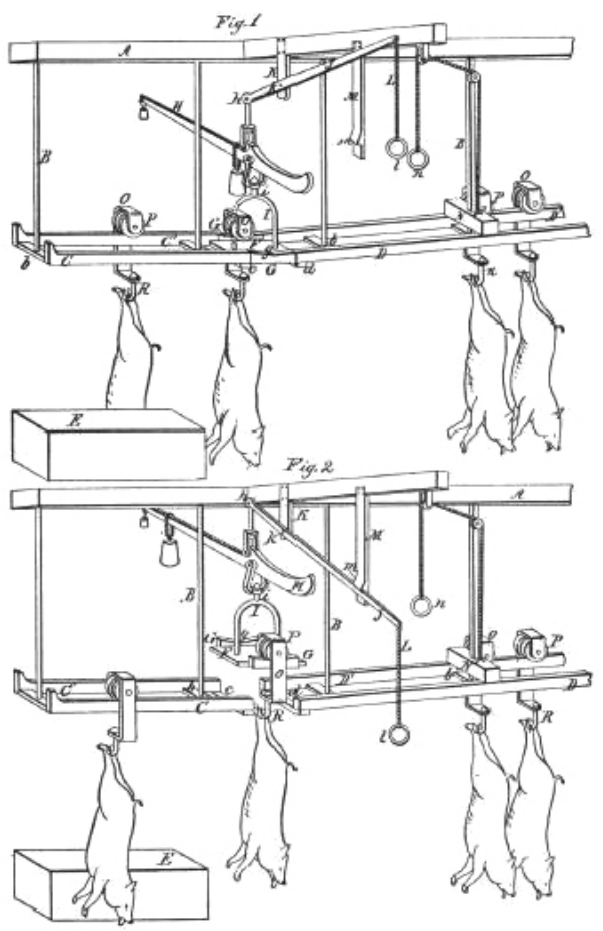

ápice de significación y especificidad. La linea de montaje, según los autores que se han dedicado a su estudio, ${ }^{1}$ proviene de la sintesis de numerosas prácticas previas de otras industrias como la fabricación de armas y sus piezas intercambiables, la producción de bicicletas, envasado de carne, fabricación de acero y de cerveza. ${ }^{2}$ Pero la relación entre cadena de montaje y ferrocarril, ha sido estudiada de forma explícita y detallada por Sigfried Giedion (1970). Giedion sitúa el origen de la cadena de montaje, con las pioneras experiencias de los molinos mecánicos de Oliver Evans y, lo conecta directamente con la tecnología ferroviaria, a través del uso de los raíles suspendidos y carros que deslizan en ellos de los mataderos de Cincinnati (figura 2). ${ }^{3}$

"El sistema de rieles superiores en los grandes mataderos condujo en última instancia al uso de la cinta transportadora, que no alcanzó pleno desarrollo hasta el siglo siguiente. Las vías, situadas sobre las cabezas de los trabajadores, llevaban pequeños carritos con ruedas que se dirigian mediante cadenas o rodaban por su propio peso por una pendiente. Inventado por un oriundo de Cincinnati en 1869, un dispositivo para pesar cerdos para las casas de envasado de carne, muestra cómo los carriles suspendidos -similares a los puentes grúa de J.G. Bodmer inventados alrededor de 1830- ahora se han convertido en auténticos ferrocarriles". (Giedion 1970: 95)

Giedion (1970: 88) repasa, como estadios intermedios de esta línea evolutiva tecnológica, algunos casos que nos interesan especialmente por su conexión con las fábricas de Kahn, como el invento por parte de Bodmer (1786-1864) del puente grúa, o el uso de un ferrocarril elevado sobre Broadway con un habitáculo suspendido con un funcionamiento similar. En todos estos ejemplos, queda patente la conexión funcional entre el ferrocarril y el paquete de inventos mecánicos que posteriormente constituirian la maquina total fordista de Highland Park.

Concluiremos en que hay una total sinergia funcional entre todos los elementos que constituyen la maquina fordista: la cadena de montaje, el puente grúa, las lineas de transporte elevadas, los toboganes, las tolvas y el ferrocarril. Esta analogía funcional, que establece un linaje técnico basado en lo que podríamos denominar como el "principio ferroviario", está también presente en el otro invento que transformó la cultura y el pensamiento occidental en los inicios del siglo XX, el cine. 


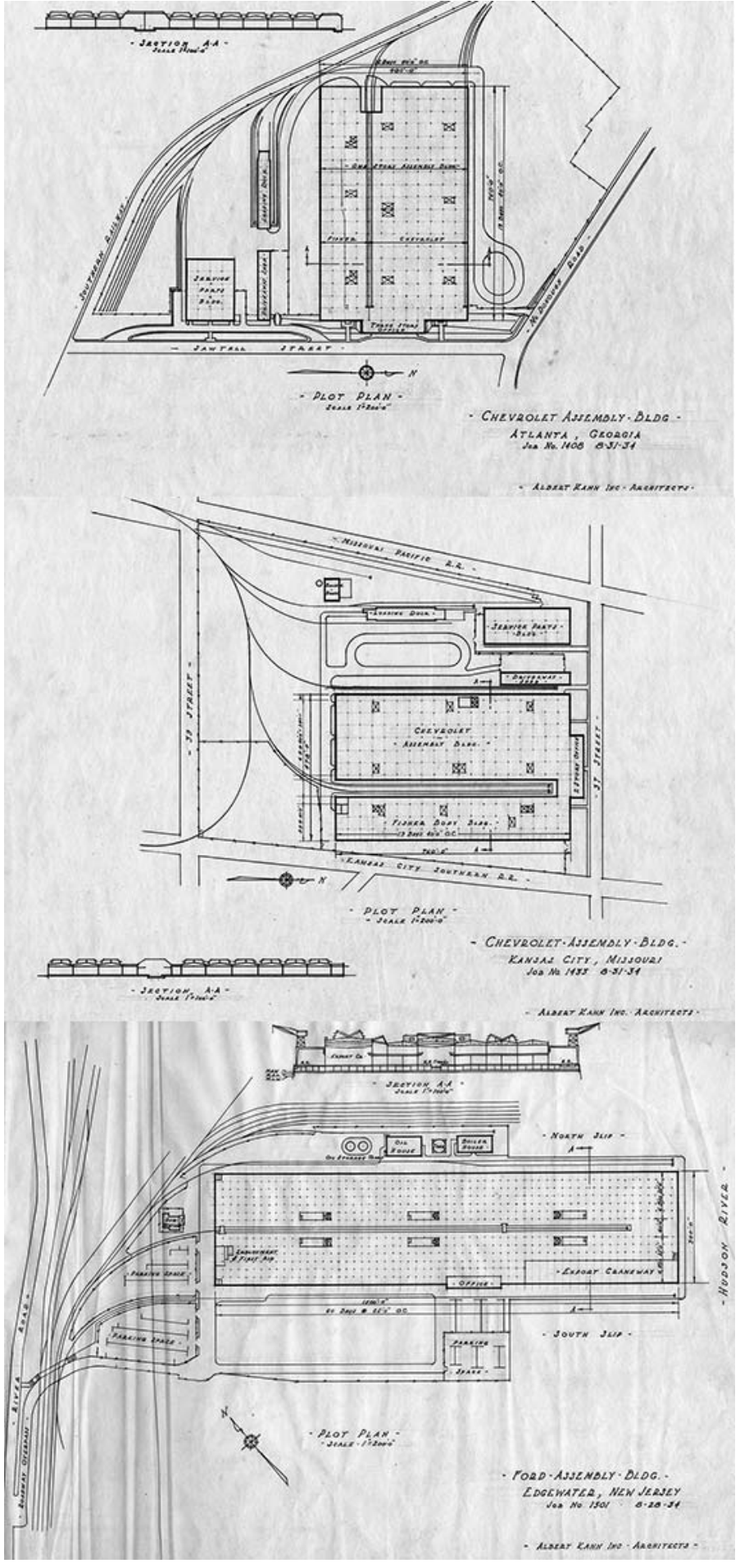

Figura 3. De arriba a abajo. Ford Assembly Building. Edgewater, New Jersey; Chevrolet Assembly Building. Kansas City, Kansas; Chevrolet Assembly Building. Atlanta, Georgia. Drawer 331, folder 5. Albert Kahn Papers, Albert Kahn Associates Inc. and the Bentley Historical Library, University of Michigan. de ensamblaje en cadena, tenía la necesidad de una continuidad total en el flujo, en el ritmo de llegada de materias primas y en la distribución de productos acabados, por lo que la conexión ferroviaria era esencial en todos los casos, al igual que la conexión a otras vías de transporte de material como las fluviales o maritimas. No es extraño que muchas de las fábricas de las que vamos a hablar a continuación tengan una organización en planta similar a la de una estación.

Por último, destacar un dato no menos revelador que los anteriores. Julius Kahn comenzó su vida profesional precisamente como empleado de una compañía dedicada a la construcción de puentes ferroviarios, la Union Bridge Company de Nueva York, entre cuyas obras se cuenta el Niagara Cantilever Bridge, un importante precedente para las estructuras en voladizo posteriores realizadas en Albert Kahn Inc. Julius Kahn fue también empleado en la C. W. Hunt Co, ${ }^{4}$ que se dedicaba entre otras cosas al diseño de infraestructuras e instalaciones ferroviarias.

\section{Uso tipológico de la tradición en Albert Kahn Inc}

Un vez explicada la primera hipótesis, con la que se pretende conectar a Albert Kahn con la tradición de la ingeniería ferroviaria norteamericana, esta debe ser complementada con otra hipótesis, de carácter metodológico, que pretende esclarecer cuál es el modo en que se hace efectiva esta conexión. Esta segunda hipótesis, se apoya en la idea de que Kahn transporta y traduce los métodos y herramientas proyectuales desde la ingeniería ferroviaria hacia su propia arquitectura industrial por medio de un procedimiento tipológico.

Para definir en qué consiste este método tipológico de transferencia de la tradición, diremos que la tipología es entendida en este contexto como un proceso asociado a la temporalidad lineal y cronológica de la historia, y se basa en la búsqueda de similitudes para obtener la raíz común de fenómenos dispares. El tipo es "un concepto que describe una estructura formal" (Martí Aris 1993: 16), derivando de esta definición primaria tres implicaciones: "el tipo tiene un carácter conceptual, no objetual, engloba a una familia de objetos"; comporta un "enunciado lógico que se identifica con la forma general de estos objetos" o fenómenos integrantes, y se refiere a la estructura formal, sin importarle la apariencia externa de los fenómenos, su fisonomía" (Martí Aris 1993: 16). La tipología se basa en el carácter evoluti- 
vo y selectivo de la tradición considerada como un sistema, no se fundamenta en una imitación de modelos u objetos particulares ni de las formas en sí mismas, sino en una imitación del ideal.

Las operaciones de transformación del tipo revisten infinidad de modalidades: yuxtaposición, adición, sustracción, combinación, cambio de escala, superposición, inversión, simetría, son algunas de las herramientas básicas del proyecto basado en el método tipológico, y producen la variación, hibridación y mutación del tipo o estructura elemental primigenia. ${ }^{5}$ Es necesario resaltar también la importancia de la fricción que se produce entre la noción de tipo y la de lugar, de la que es producto la arquitectura como fenómeno material radicado de forma inevitable y permanente en una ubicación geográfica determinada. El tipo se refiere a lo genérico, a lo universal y abstracto, mientras que el lugar es singular, concreto y particular. Esta dualidad se puede estudiar óptimamente en Kahn en el caso del conjunto de su producción, en la que un mismo programa se adapta a varios lugares diferentes por medio de la manipulación tipológica o la evolución e hibridación a partir de un mismo tipo. En otros casos, como en la arquitectura industrial a partir de Highland Park New Shop, la desvinculación de la arquitectura del concepto de lugar y su alineación con el concepto de objeto técnico de Gilbert Simondon (1956), nos permite valorar la idea de tipo, no sólo como un procedimiento de análisis de la esencia de las obras arquitectónicas, sino como un método operativo, como una herramienta estratégica del acto proyectual, y como tal se estudiará apoyándonos en la obra industrial de Kahn.

Un vez planteadas las dos hipótesis de partida que establecen la conexión de Kahn con la tradición ferroviaria y el modo de funcionamiento de esta conexión, pasaremos a analizar la presencia de los tipos provenientes de esta tradición en la obra de Kahn, e intentaremos desvelar en qué modo el uso del método tipológico, permitió la transformación de estos tipos primigenios en otros nuevos, susceptibles de ser a su vez adoptados por la arquitectura del primer funcionalismo de vanguardia del siglo XX.

La conexión de la arquitectura de Kahn con tipos provenientes de la tradición de la ingeniería ferroviaria americana, va más allá de las estaciones para pasajeros antes citadas y se extiende a otros tipos fundamentales de esta tradición, como son, por un lado, los puentes ferroviarios, y por otro, los depots, trainsheds, enginehouses y freighthouses del siglo XIX americano.

\section{Terminales de pasajeros, Depots, Trainsheds, Enginehouses y Freigh- thouses americanas}

La estación de ferrocarril, como el resto de los tipos ferroviarios que estudiaremos a continuación, es un tipo arquitectónico nuevo creado en la década de 1830. Aunque no fue hasta 1870 que empezaron a construirse estaciones americanas de dimensiones comparables con las europeas, el invento del ferrocarril se puede considerar simultáneo en Inglaterra y en los Estados Unidos. El nuevo invento combinaba cuatro elementos principales: una vía especializada, el transporte de pasajeros, el transporte de cargas y la tracción mecánica. ${ }^{6}$

Las primeras estaciones de pasajeros construidas en el mundo, fueron la estación de Liverpool, de 1830 y la de Lowell, Massachusetts en 1835. Los planos más antiguos conservados de este tipo arquitectónico, fechados en 1835, son los de la Car House de la compañía Boston and Lowell Railroad (Meeks 1995: 169).

Como pasó con cualquier otro tipo arquitectónico de nueva creación, en la estación de ferrocarril se iniciaron numerosas lineas evolutivas experimentales que luego serian abandonadas. Sin embargo, ya en 1846 , se puede encontrar una primera clasificación del tipo. Esta clasificación tipológica consta de cuatro categorías: estación en cabeza (situada al final de los andenes), estación gemela (estación dividida en dos edificios situados a ambos lados de los andenes), estación lateral (estación situada a un lado de los andenes) y estación en L (combinación de los tipos en cabeza y lateral). ${ }^{7}$ Dentro de estos tipos podía haber otros subtipos, que se reúnen en un interesante diagrama recopilatorio (figura 4) (Meeks 1995: 30).

Dos tipos se impusieron al resto. La estación gemela y en U se impuso en estaciones terminales de pasajeros y, el esquema lateral, en estaciones intermedias o de pequeño tamaño. En cuanto a los tipos específicamente americanos, Meeks (1995: 50) nombra uno que se adapta al esquema bilateral, pero incluyendo el espacio de la trainshed y de las estaciones bajo una misma cubierta. Es el tipo train barn americano, cuyo primer exponente fue la estación de Syracuse en Nueva York, de 1838. Este tipo tiene su conti- 
A. EARLY TYPES OF STATION PLAN

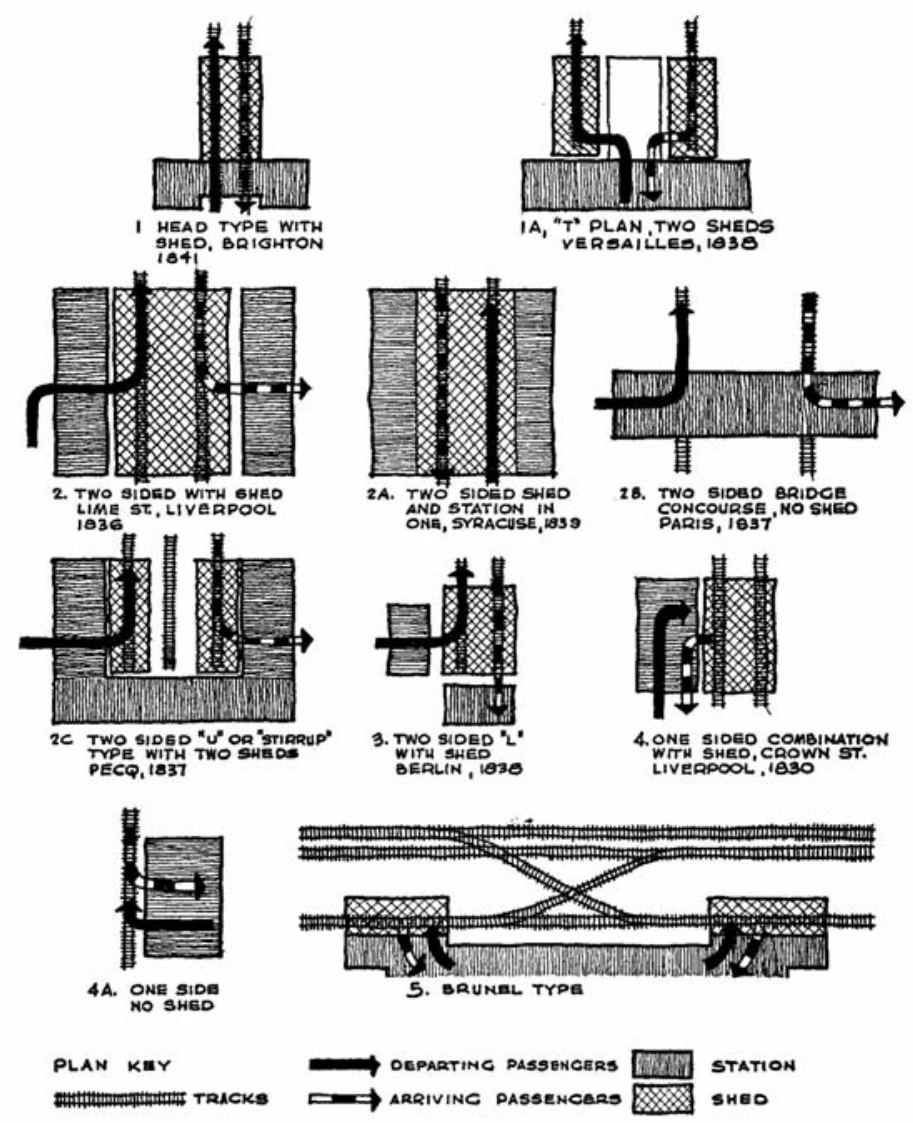

Figura 4. Tipos de estaciones. (Meeks 1995)

Figura 5. Sección trasversal de la estación de Meanville, Pennsylvania, de la Atlantic and Great Western Depot (1862). (Condit 1960). La sala de espera estaba en la izquierda, la cubrición de los trenes en el centro y el restaurante a la derecha. nuación en las numerosas American depots construidas en la Costa Este, cuyos mejores representantes son la estación de Meanville, Pennsylvania (figura 5) y la de Columbus, Ohio. ${ }^{9}$ La primera de estas estaciones, que media $300 \times 120$ pies (91.44x36.58 metros), estaba formada por tres espacios paralelos con distinto uso, organizados bajo una misma cubierta. La trainshed central, cubría una luz de 66 pies (20.12 metros) y tres lineas de vías, por medio de una cercha triangulada con un cordón superior de madera, con diagonales a tracción y cordón inferior de hierro forjado, y puntales de hierro fundido huecos. Las naves laterales, sala de espera y restaurante respectivamente, se cubrian con cerchas de madera (Condit 1960).

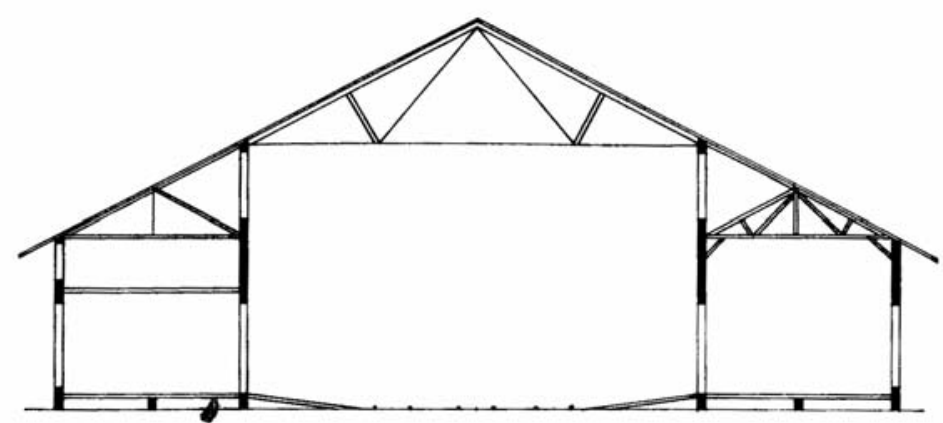

Este tipo de solución desarrollada sólo en una planta, hacía que los pasajeros tuviesen que cruzar las vias para llegar desde la sala de espera al restaurante, lo que llevo, junto con el crecimiento del número de líneas de raíles, cada vez más a la adopción de una trainshed separada respecto de la estación.

Un ejemplo de este tipo de trainshed independiente es la Dearborn Station de Chicago (figura 6), 10 medía $165 \times 600$ pies (50.29x182.88 metros) y estaba compuesta por tres naves. Las laterales, más bajas, tenían una estructura de cercha de madera. La nave central, de 65 pies (19.81 metros) de luz, es especialmente interesante al estar formada por dos cerchas superpuestas que conforman un lucernario por el que entra la luz y sale el vapor y el humo de los trenes. Entre las cerchas laterales y la central existen otras ventanas verticales que iluminan la nave principal, estableciéndose un efectivo sistema de iluminación del espacio interior.

Otros ejemplos especialmente valiosos de esta tipologia de la independent trainshed son la Central Station de Chicago de 1892-93 (figura 7) ${ }^{11}$ y la North Station de Boston de 1891-94. La primera estructura se puede interpretar como dos cerchas con un doble voladizo, que se compensan mediante su articulación en el centro de la nave principal de 108 pies (32.92 metros). Los voladizos laterales de 36 pies (10.97 metros) y el lucernario central completan la serie de elementos existentes en esta estación, que tienen relación con las obras de Kahn que veremos a continuación. Otra trainshed independiente es la Illinois Central Railroad Station de Nueva Orleans (figura 7), ${ }^{12}$ una estructura en la que el mismo sistema de dobles voladizos articulados y lucernarios empieza a producir una estructura extendida horizontalmente. Esta estación es descrita en el principal libro de referencia sobre estructuras ferroviarias, de la siguiente manera:

"El diseño de esta estructura es novedoso y original. Se compone de tres vanos en arco, con dos proyecciones del techo mediante dos voladizos laterales. La luz completa cubierta es de 148 pies (45.11 m). El tramo central es de 41 pies (12.50 $\mathrm{m})$ de ancho y 30 pies $(9.14 \mathrm{~m})$ de altura en centro del vano sobre las vías. Los vanos laterales adyacentes son cada uno de 36 pies $(10.97 \mathrm{~m})$ de ancho y 22 pies y 6 pulgadas $(6.86 \mathrm{~m})$ de alto en el centro del vano. Las proyecciones del techo a cada lado se extienden 17 pies y 6 pulgadas $(5.33 \mathrm{~m})$ desde el pilar lateral". (Berg 1893: 422) 


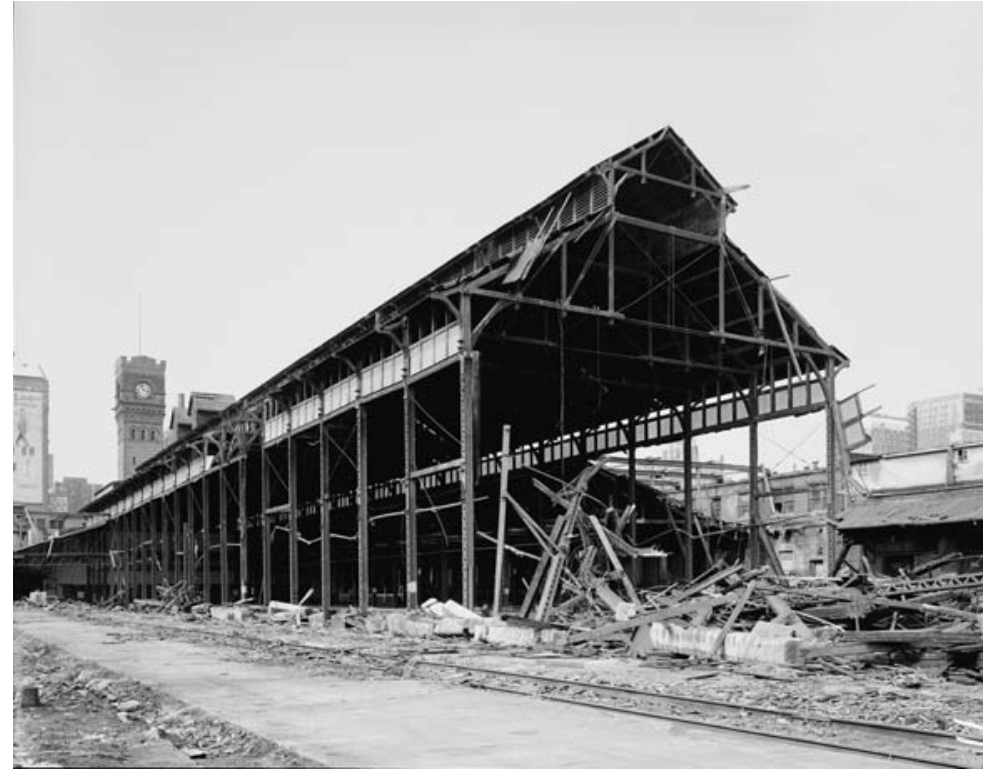

Izquierda. Figura 6. Dearborn Station Chicago 1883-85. Library of Congress. USA-HAER

Derecha. Figura 7. De arriba a abajo. Illinois Central Station de Nueva Orleans; Illinois Central Station de Chicago; de B. L. Gilbert. (Condit 1960). Módulo estructural con voladizos laterales de la Half Ton TruckPlant de Chrysler. Albert Kahn 1937 (Nelson 1939).

Figura 8. North Station de Boston. (Condit 1960)
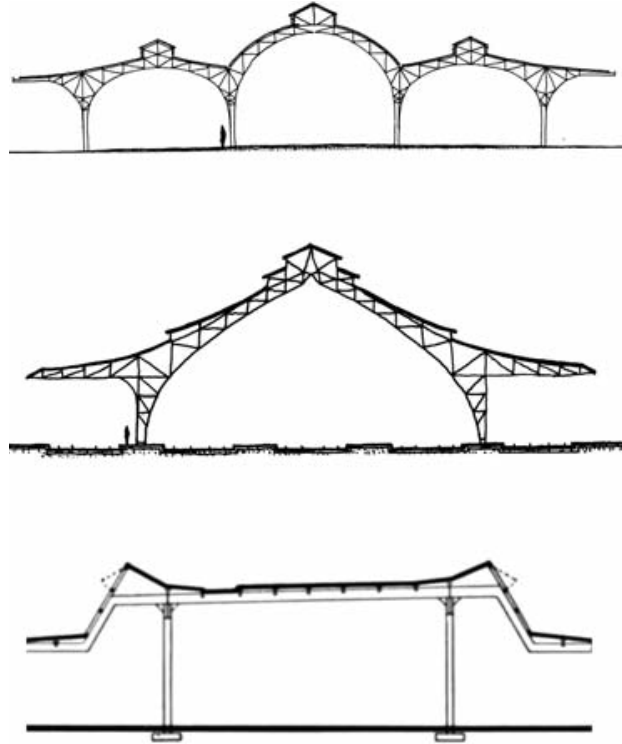

vas naves industriales que Albert Kahn construiría posteriormente para la industria aeronáutica.

Pero aún subsistía un problema funcional irresuelto en las primitivas estaciones: la comunicación en el sentido transversal a las vías. Este problema era especialmente grave en las terminales de carga, en las que la llegada y salida de materiales se combinaba con el transbordo y almacenaje temporal de los mismos. En el caso de las trainsheds de pasajeros, la solución adoptada de forma más generalizada sería la de crear un basamento con pasajes bajo las vías que conectasen con cada uno de los andenes por medio de escaleras. En cambio, en las terminales de carga o freighthouses o de reparación o enginehouses, el problema se aborda de una

forma más completa.
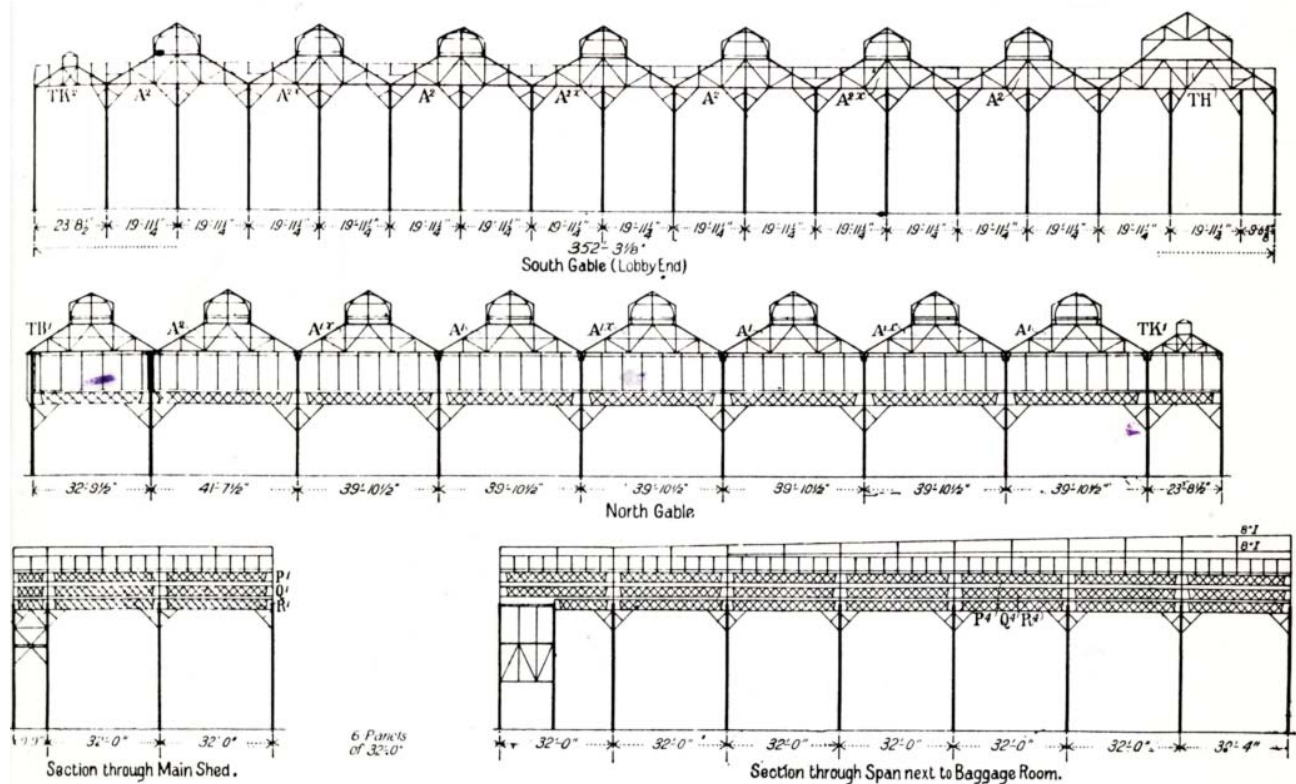


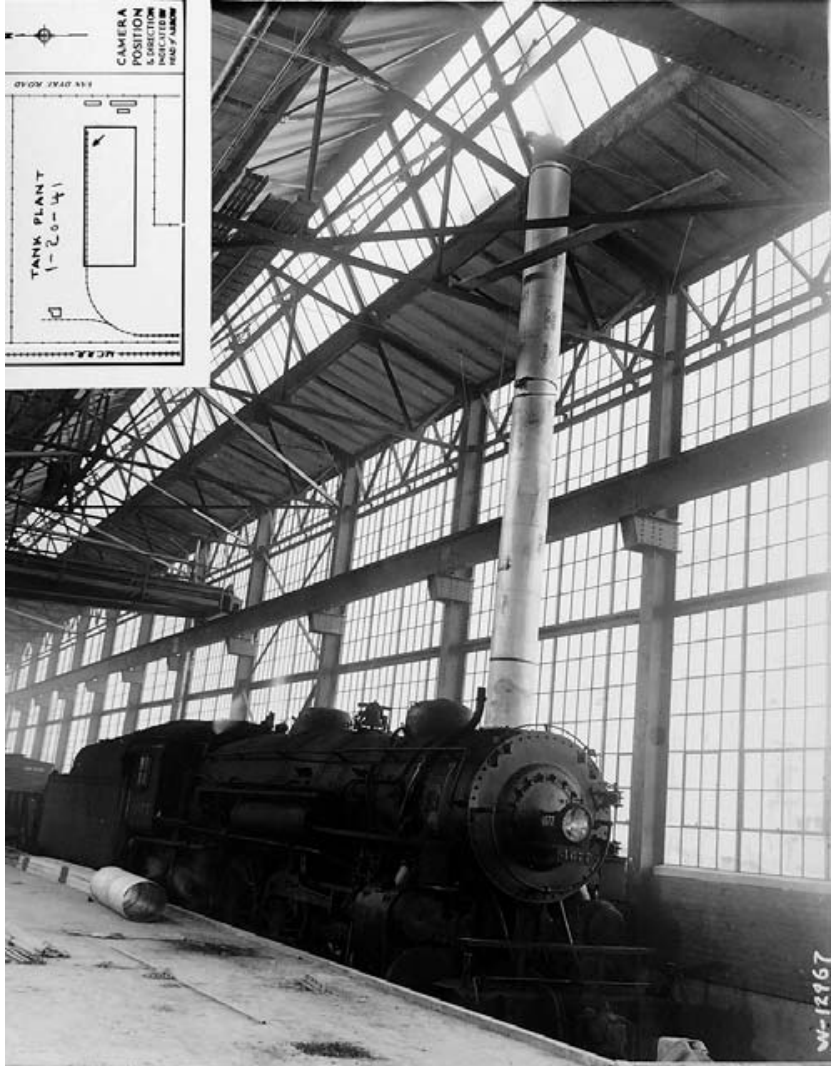

Figura 9. Chrysler Corporation, Tank Arsenal. Detroit, Michigan 1940. Box 5. Albert Kahn Papers, Albert Kahn Associates Inc. and the Bentley Historical Library, University of Michigan.
Estos dos nuevos tipos constructivos, combinaban una serie de mecanismos arquitectónicos, que, junto a los estudiados con anterioridad, veremos repetidos sistemáticamente en la obra industrial de Kahn. Estos nuevos mecanismos, se pueden resumir en el uso de un basamento transitable, la verticalización y mecanización de la circulación de materiales, y el apilamiento de los espacios de almacenamiento con la consiguiente verticalización del espacio requerido para el movimiento de la carga.

El primer tipo, las enginehouses, eran edificios auxiliares situados cerca de las terminales o en las estaciones de transbordo. Se usaban para realizar labores de mantenimiento, limpieza de las máquinas entre dos viajes y reparaciones en las locomotoras. Podian ser rectangulares o poligonales (roundhouses) (Berg 1893: 167). Las dos características más relevantes de estos edificios son, la presencia de trincheras excavadas con un suelo metálico mecanizado, usadas para poder hacer reparaciones debajo de los trenes y para poder drenar el agua y los productos usados para la limpieza, y el uso de chimeneas o extractores, que debian atravesar la cubierta o la fachada del edificio y conectarse directamente a la chimenea de la locomotora. Estas chimeneas en muchos casos tenían partes móviles para poder adaptarse a las diferentes alturas de las diferentes maquinas (Berg 1893: 169). Las plataformas inferiores se podian mover para colocar a los trenes en la posición requerida. El tipo que se impuso fue la roundhouse aunque autores como Berg, recomiendan, aún en 1900, el tipo lineal con diferentes naves y cubierta en diente de sierra y múltiples chimeneas, por su facilidad de ampliación y de operación simultánea en diferentes trenes (Berg 1893: 175). Éste es el tipo que, como veremos más tarde, se relaciona con Highland Park New Shop, convirtiendo las chimeneas en los soportes estructurales del propio edificio (figura 9).

Un ejemplo bastante genérico del tipo es la enginehouse en Mt. Pleasant Junction, Jersey City, NJ (figura 10). ${ }^{14}$ En la sección de esta roundhouse se pueden ver con claridad los elementos del suelo elevado mecanizado y las chimeneas, combinados con un lucernario central. En la enginehouse en East Mauch Chunk, Pennsylvania (figura 11), ${ }^{15}$ estas características se combinan con una estructura en diente de sierra formada, no por cerchas biapoyadas como en el anterior ejemplo, sino por dobles voladizos en forma de paraguas lineal, que se articulan uniéndose en sus extremos. Este modesto uso del voladizo, junto con la linealidad del edificio, que agrega los andenes de reparación horizontalmente de forma potencialmente ilimitada, se convierte en un precedente, no solo para Highland Park New Shop, sino también para ciertas estructuras basadas en la repetición del voladizo en Kahn, como la Half Ton Truck Plant de Chrysler o la segunda ampliación de la nave de ensamblaje para Glenn L. Martin.

El otro tipo edificatorio es la freighthouse, terminal de carga, descarga e intercambio de fletes (figura 12). Muchas de ellas se situaban sobre muelles y servian de intercambiador con el transporte marítimo. Este tipo inicial consistía en una construcción de una planta situada sobre una plataforma elevada o un muelle, con una sección escalonada con iluminación lateral y descarga manual a nivel. Un ejemplo de este tipo inicial es la freighthouse de Newark, Nueva Jersey. ${ }^{16}$ Otros ejemplos de un nivel en los que se pueden ver otras características, como los lucernarios o mecanismos manuales de descarga, son la terminal freight-pier shed en Jersey City, NJ, de la Lehigh Valley Railroad Company o la terminal freight-pier shed en la misma ciudad, de la Pennsylvania Railroad, con puertas de batiente horizontal colgadas de la estructura. 
Figura 10.

Enginehouse en Mt. Pleasant Junction, Jersey City, NJ de la Pennsylvania

Railroad. Sección y planta (Berg 1900)

Abajo.

Columna izquierda. Figura 11. Walter Berg. Enginehouse en East Mauch Chunk, $\mathrm{Pa}$, de la Leight Valley Railroad Company. Secciones y planta (Berg 1900)

Columna derecha.

Figura 12.

Freighthouses. (Berg 1900)
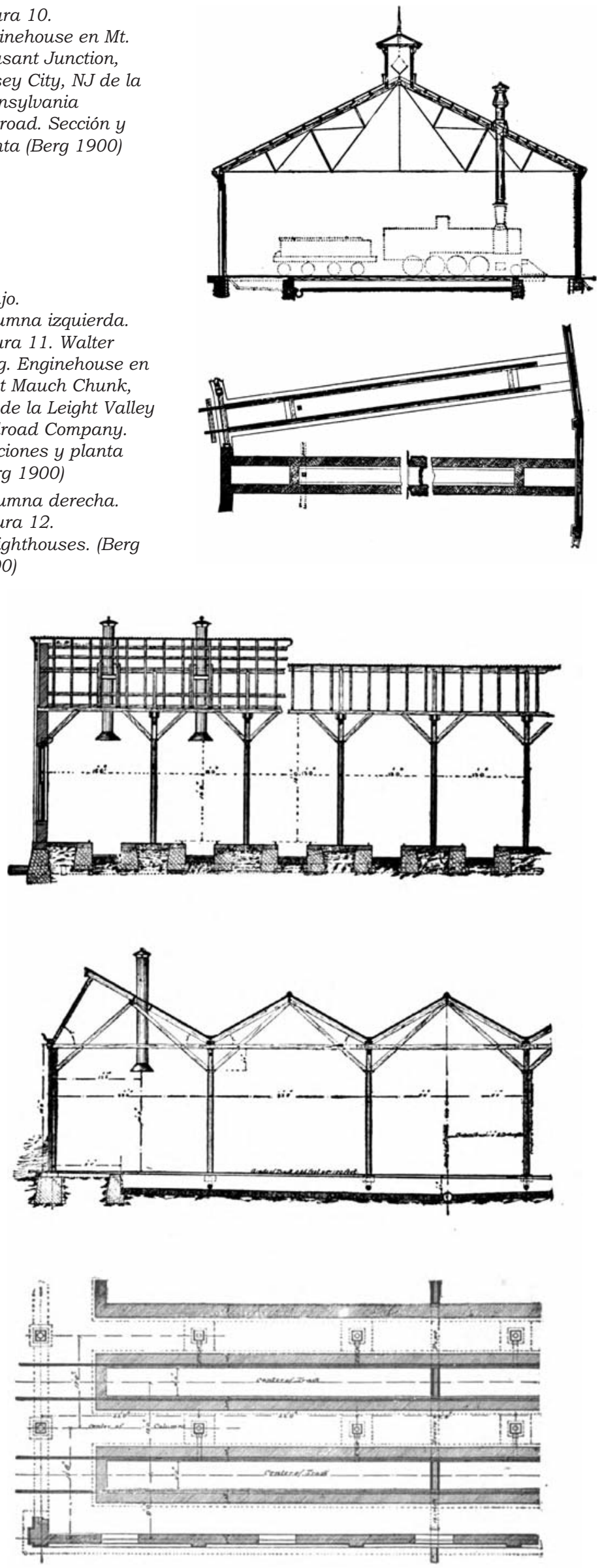

El tipo evolucionó pronto hacia un edificio de dos plantas sobre muelle y descarga vertical mecanizada con almacenaje en la planta superior. Ejemplo de esto es la double storey freight pier shed, terminales G y $\mathrm{H}$, en Jersey City, NJ (figura 13). ${ }^{17}$ Las vías penetran en el edificio de forma romboidal y la carga se desplaza de forma vertical gracias a elevadores de barriles de vapor tipo Rudell. Ya no hay forjado sobre las vías, con lo que vemos que se empieza a crear el espacio vertical de descarga que luego derivaría en el espacio del puente grúa de Highland Park. Las ventajas de este espacio vertical son explicadas por Berg de la siguiente manera:

"Al omitir la planta superior sobre las vías, la altura del edificio se redujo, mientras que la ventilación y la iluminación de
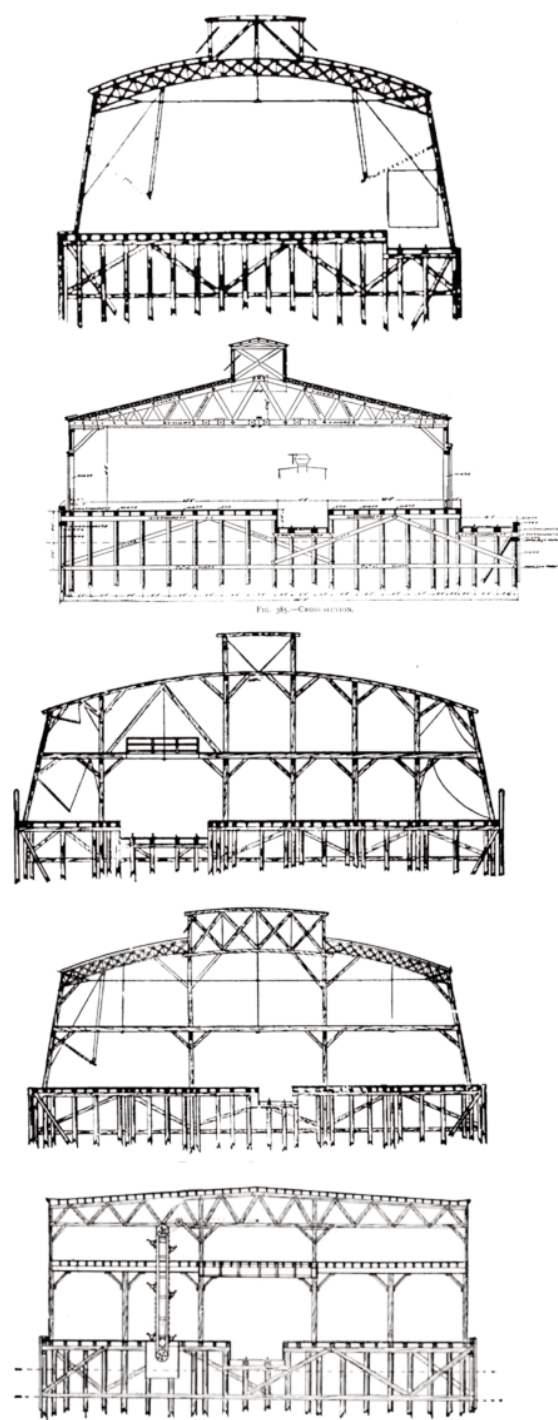
Figura 13. Double storey terminal freight pier shed New Jersey City. N. J. Lehigh Valley Railroad Co. Alzado, planta y sección transversal (Berg 1900) la planta se facilitaron enormemente, y se evitó la construcción de vigas pesadas y costosas para cubrir la luz sobre las vías por supuesto, esto supuso una cierta pérdida de espacio de almacenamiento". (Berg 1893: 229)

Así, en este edificio ya se pueden detectar numerosas características tipológicas transportadas con posterioridad a la arquitectura de Kahn, como son las plataformas inferiores con vías rehundidas, la sección con estructuras superpuestas conformando lucernarios, los medios mecánicos de descarga, que derivan en una verticalización del espacio de descarga y la conversión de este espacio en el espacio central del edificio. ${ }^{18}$
Las razones para esta verticalización se pueden hallar en la necesidad de aumentar la capacidad de almacenamiento de las freighthouses y abaratar los costos de la ocupación de suelo en las ciudades. Pero la creación de nuevos métodos de carga, descarga y movimiento de materiales fueron los motores reales de esta transformación. El primitivo transporte interior de materiales en las freighthouses se realizada normalmente con carros de tracción humana. Estos medios se sustituyeron pronto por una serie de nuevos dispositivos como las tolvas y toboganes, los teleféricos y puentes grúa, las cintas transportadoras inclinadas, verticales u horizontales y los montacargas (Allison 2014: 101). Aunque se habían usado montacargas en Estados Unidos antes de 1900, fue,
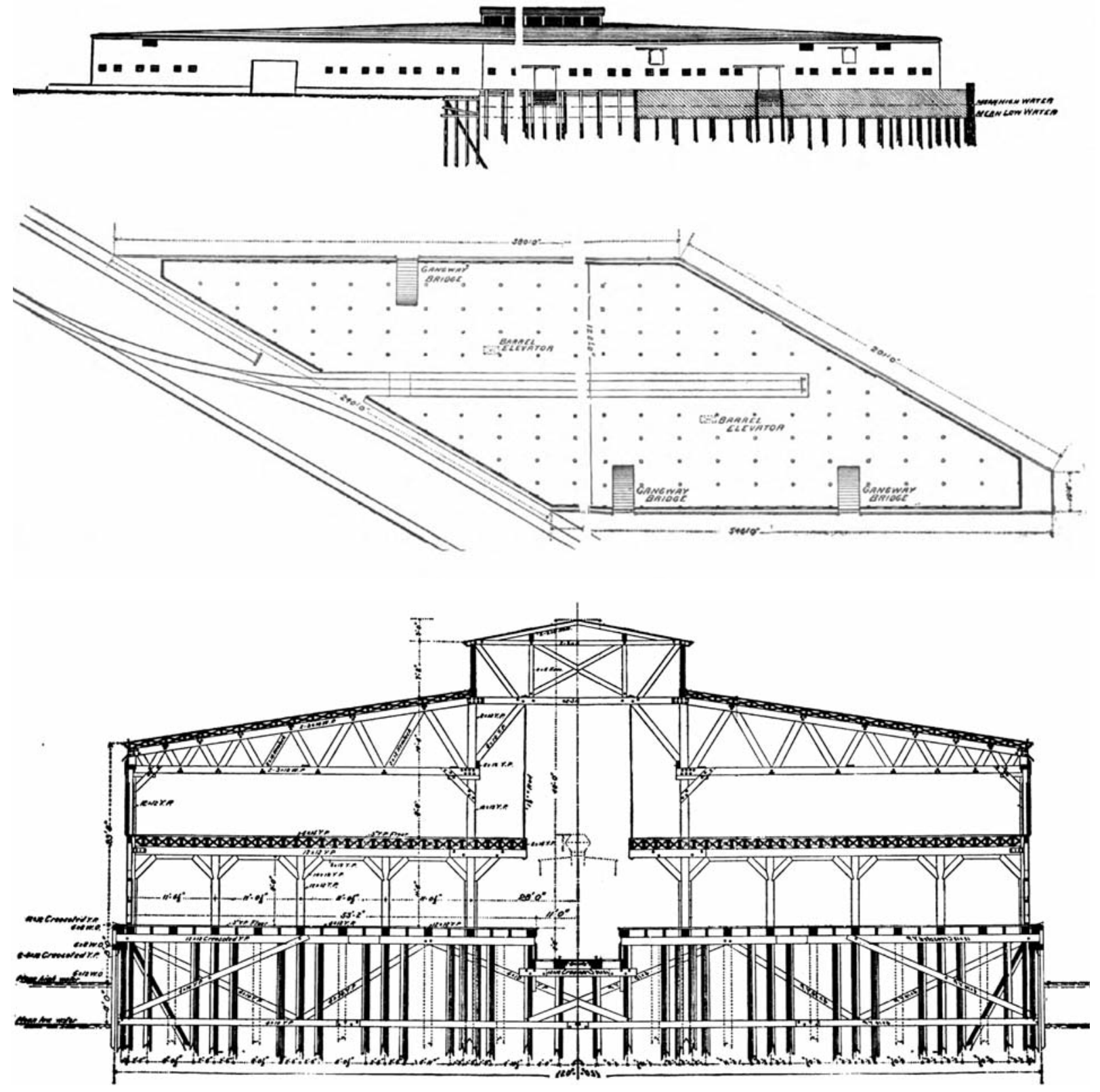

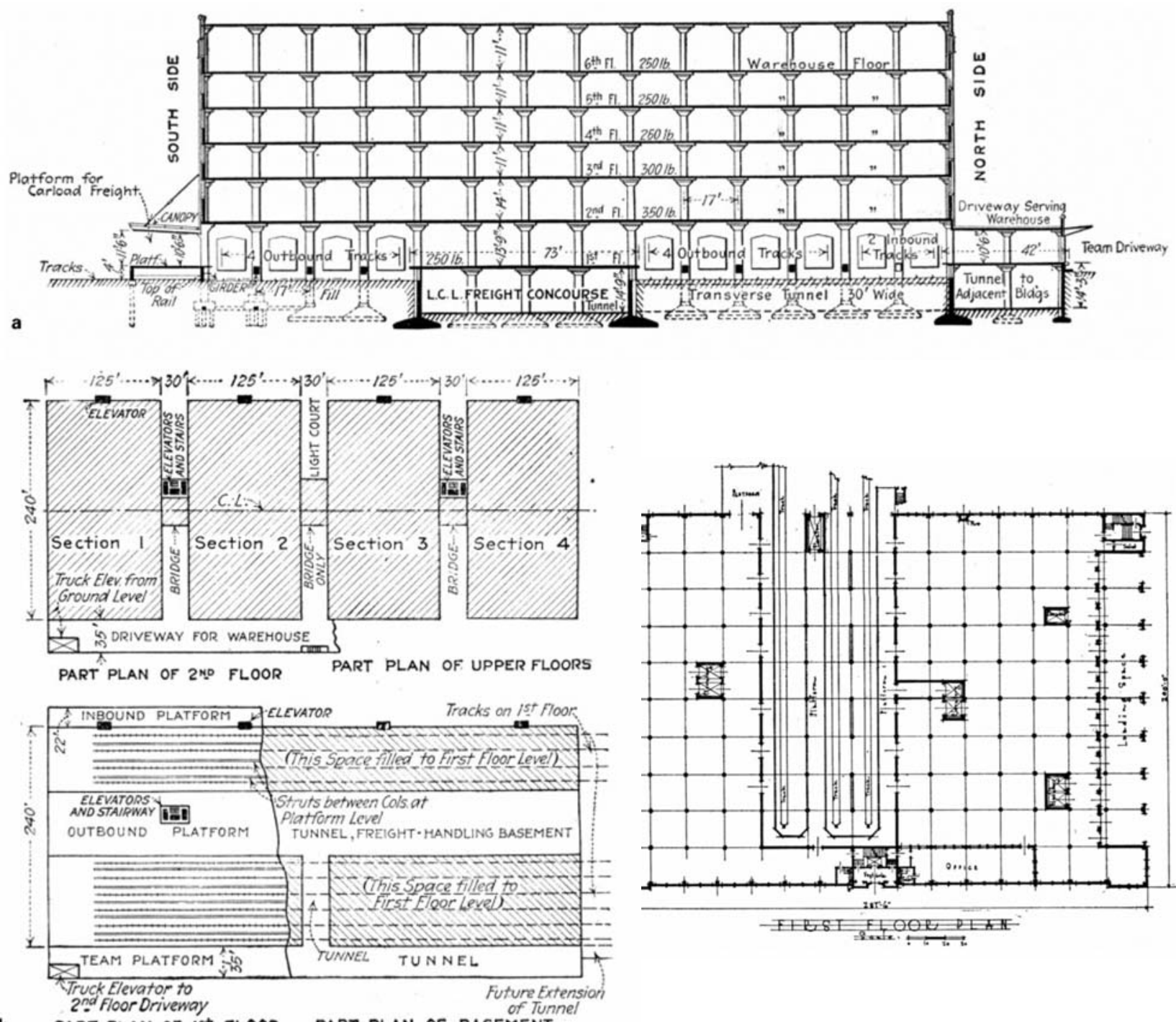

b PART PLAN OF ISt FLOOR PART PLAN OF BASEMENT
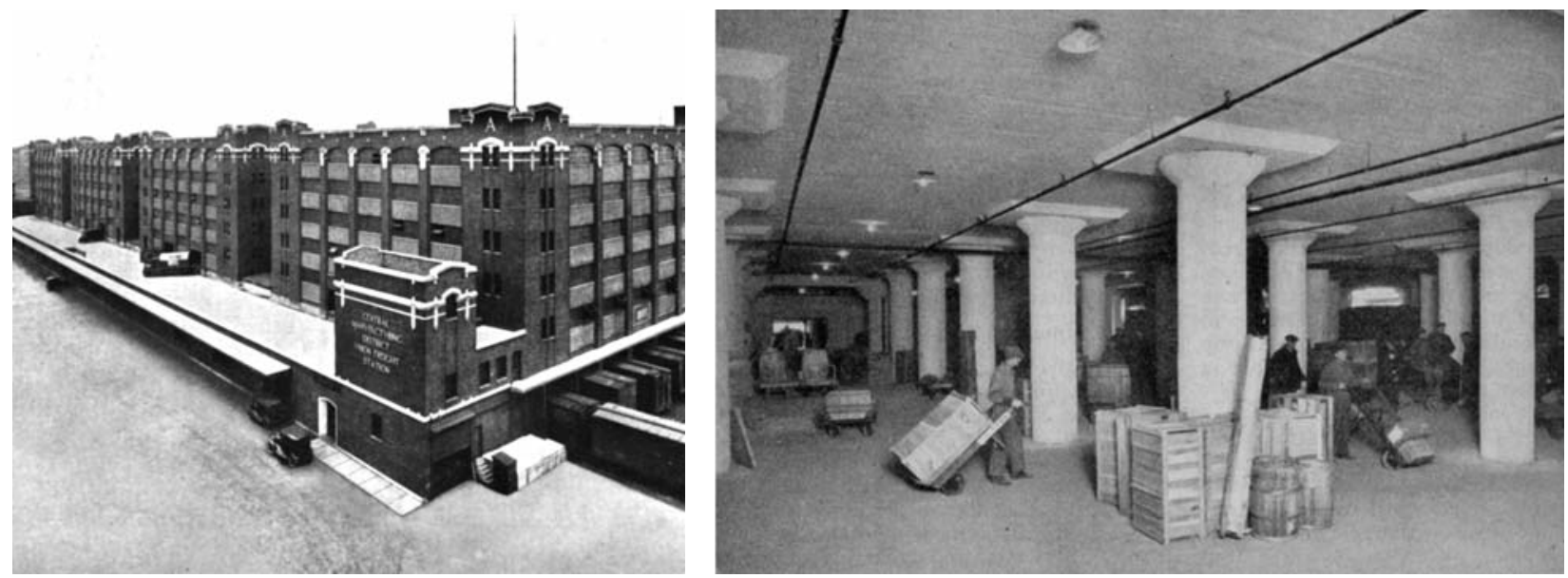

Figura 14. Union freighthouse $A$ y $B$ de la Chicago Junction Railway. (Allison 2014) tras la invención por OTIS del montacargas con tracción eléctrica sin engranajes y con controles automáticos, cuando se generalizó su uso y se impuso al resto de los mecanismos de descarga en las freighthouses (Allison 2014: 117). Estos montacargas, permitian el transporte vertical de cuatro o cinco camiones simultáneamente (Allison 2014: 101). Vemos que el tipo sufre una evolución debido a una de las características más claramente identificables dentro de las fábricas clásicas del fordismo: el movimiento continuo e ininterrumpido de materiales. 
Izquierda. Figura 15. Edificio B de la Navy Yard de Brooklyn. (Christen y Flanders 2001)

Derecha. Figura 16. Highland Park New Shop. Patio interior.1914. (Ferry 1970)
La verticalización del espacio debida a esta necesidad funcional se puede ver claramente en dos freighthouses construidas en 1917 y 1918, inmediatamente antes y después que Highland Park New Shop: la Union freighthouse A y B de la Chicago Junction Railway y el Edificio B de la Navy Yard de Brooklyn. En el primer caso (figura 14), los espacios verticales se disponian en perpendicular a la circulación de los trenes en planta baja. Estos estrechos espacios verticales entre distintas secciones se unian con puentes en los que se situaban los montacargas que conectaban los seis niveles del edificio. Los edificios situados a ambos lados de este espacio vertical, se resolvían con una malla de hormigón armado con losa plana y pilares con capitel similar a Highland Park New Shop.

El otro caso de estudio es el Edificio B de la Army Supply Base del Navy Yard de Brooklyn (figura 15), que es una freighthouse de intercambio entre ferrocarril y transporte naval. Es una instalación militar en la que la mayor preocupación del diseño se centra en una rápida circulación de los materiales de guerra y viveres para las tropas desde el tren al barco. El esquema de espacios verticales y el sistema de transporte es, en todo, igual a Highland Park New Shop. Incluso los alzados interiores del edificio, con las series de voladizos, hacen del espacio central de este edificio un espacio gemelo al de la fábrica de Ford (figuras 16, 17 y 18). Esta similitud no es casual, ya que según la documentación consultada, los diseñadores de esta obra, ${ }^{19}$ contaron con la asistencia técnica de ingenieros de Ford para su construcción. ${ }^{20}$ En el edificio se adoptó una solución singular para un problema singular: como cargar los suministros de guerra en los barcos de una manera rápida e ininte-

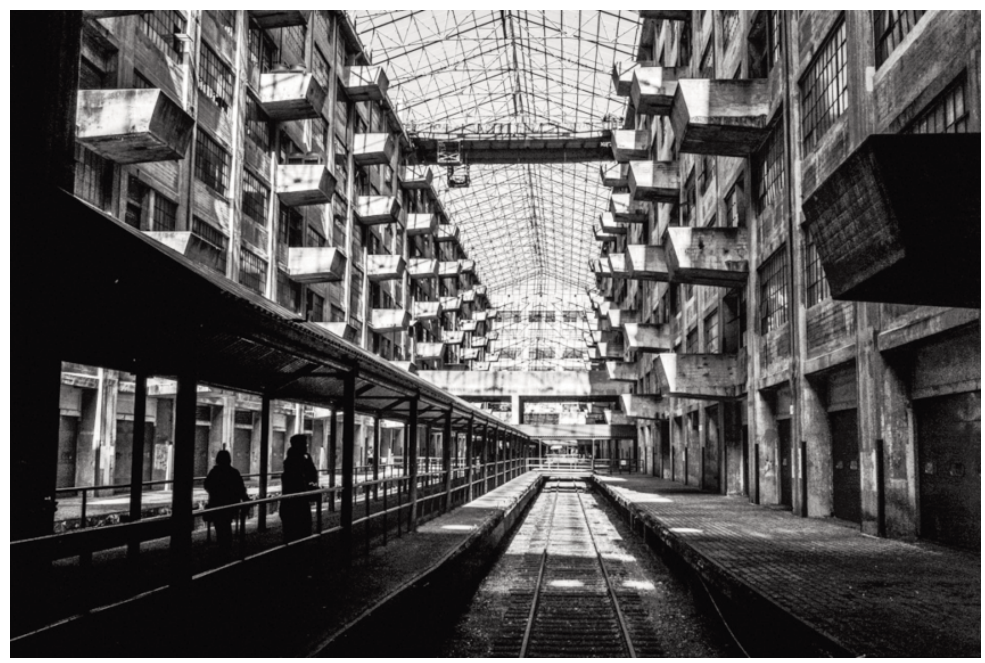

rrumpida. En este caso, como en el de Highland Park, la solución estaba en la verticalización del espacio y en el uso del puente grúa y las plataformas en voladizo.

La construcción de esta instalación, en una fecha ligeramente posterior a Highland Park New Shop, hace de ella un interesante caso de estudio que demuestra la cercanía tipológica y el parentesco formal entre las freighthouses y la ampliación de la fábrica de Highland Park. Es un caso de hibridación inversa del tipo. Highland Park y las freighthouses de los ferrocarriles Americanos son dos familias tipológicas que mantienen una relación permeable en ambos sentidos, y la vitalidad de los híbridos obtenidos mediante esta fertilización constante se hace evidente en estos dos espacios gemelos. El edificio de Cass Gilbert, bien se podría definir como una freighthouse que ha adoptado caracteristicas tipológicas de la fábrica automovilistica fordista, que a su vez, según nuestra hipótesis de partida, podría tener su origen en la propia genealogía tipológica de las primitivas freighthouses americanas del siglo XIX.21

Así, la fábrica de Highland Park New Shop, pasa a ser considerada en este trabajo, como un descendiente tipológico de las freighthouses en la que se ha completado la tendencia a la verticalización de la descarga y del espacio, con dos naves paralelas a ambos lados de la vía, como en

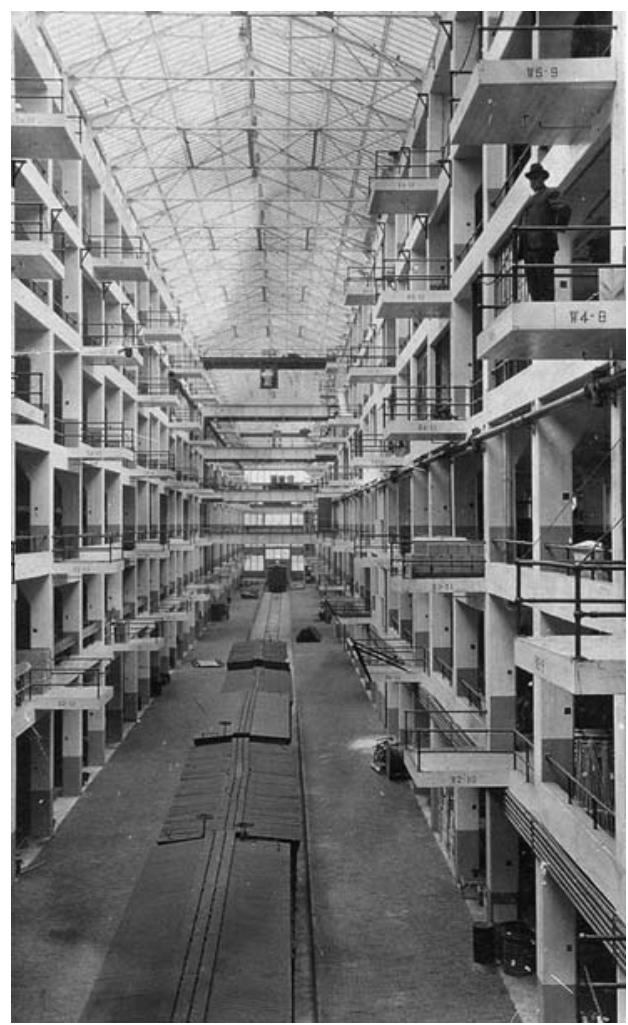



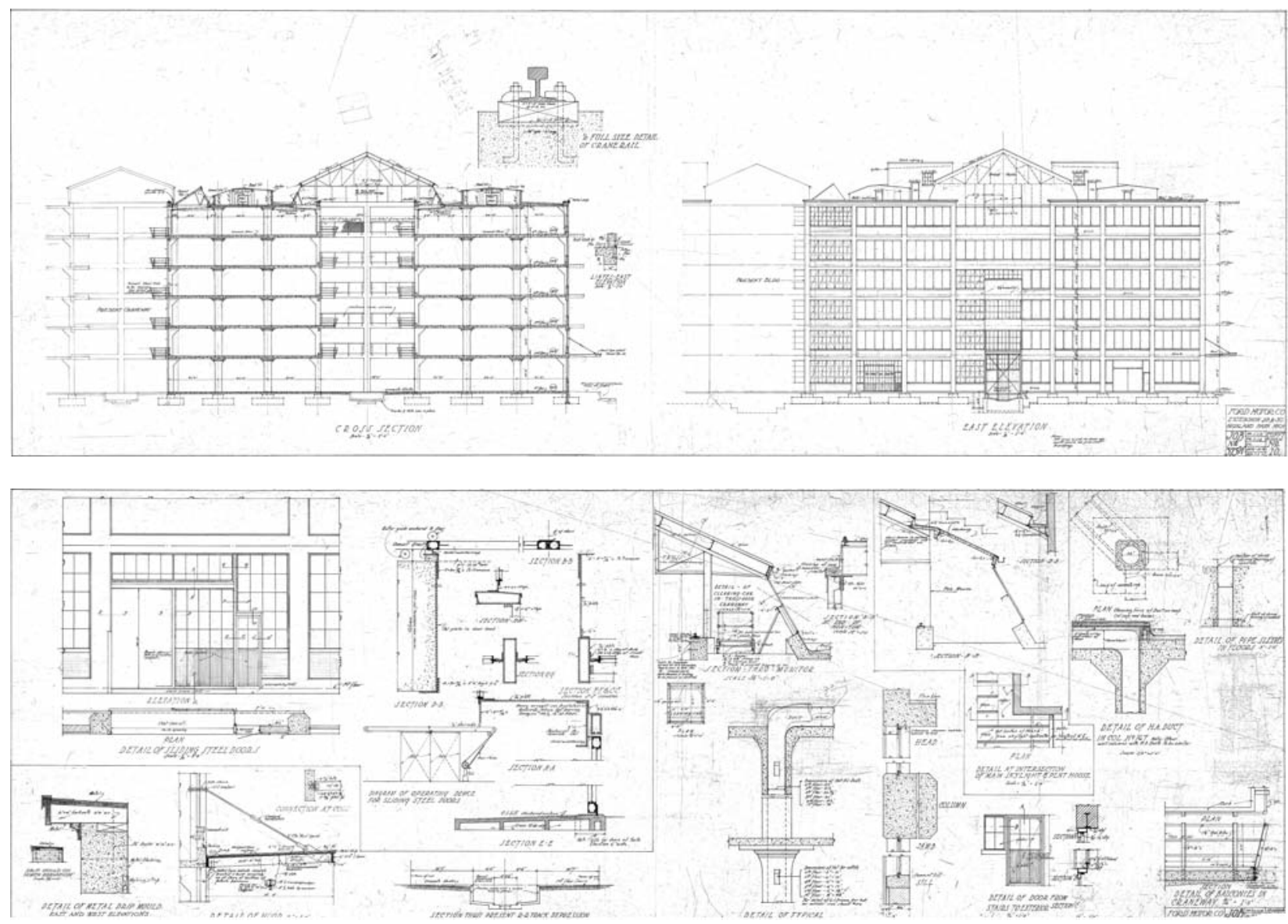

Arriba. Figura 17. Highland Park New Shop. Alzados interiores.Tube 24. Albert Kahn Papers, Albert Kahn Associates Inc. and the Bentley Historical Library, University of Michigan.

Abajo. Figura 18. Highland Park New Shop. Plano de detalle de los pilares huecos.Tube 1.Albert Kahn Papers, Albert Kahn Associates Inc. and the Bentley Historical Library, University of Michigan. las estaciones de pasajeros, y un espacio central con puente grúa y lucernario central acristalado. Otro rasgo interesante es la conversión de las chimeneas de las antiguas enginehouses, en la propia estructura del edificio, mediante la creación de pilares huecos con tubo de ventilación que conectaban con máquinas extractoras en cubierta. Este tipo de mutación tipológica, tiene un cierto parentesco con las operaciones de Stoffwechsel o pseudomorfismo de tipo semperiano. Aunque en este caso la transposición no es simbólica sino funcional, y un elemento portante sufre un proceso de agrupación de funciones dentro de una forma única.

\section{Puentes ferroviarios. El voladizo como tipo estructural}

Una vez revisadas las tipologías constructivas de las terminales de pasajeros, depots, trainsheds, enginehouses y freighthouses americanas, nos queda por estudiar la estructura estrella de la ingeniería ferroviaria de los Estados Unidos: el puente ferroviario.

Para demostrar la relevancia, trascendencia y enorme popularidad de este tipo constructivo en todas sus variantes, bastaría sólo decir que, en el siglo que va desde el año 1790 hasta 1890, se registraron más de 600 patentes de diferentes estructuras de puentes en la Oficina de Patentes de los Estados Unidos de América. 22

La explosión en el diseño de puentes se produjo para satisfacer las demandas de las pioneras empresas ferroviarias, que necesitaban un medio más rápido y barato de construir que los antiguos puentes de arcos de piedra. El primer material empleado para sustituir a la piedra fue la madera, material abundante, barato y de fácil trabajo en la Norte América del siglo XIX.

El diseño de puentes en arco pronto se abandonó en favor de la cercha bi-apoya$\mathrm{da}$, que ofrecía mayor facilidad constructiva, mayor regularidad de las piezas, una plataforma plana y horizontal para el tren y empujes verticales en los apoyos, evitando el empuje horizontal. Estas características convirtieron al puente compuesto por un cajón, cerrado o no superiormente, y con dos vigas en celosía laterales, en el estándar de la industria ferroviaria (figura 19).

En cuanto a los materiales utilizados, después de las primeras experiencias en madera, este material fue progresivamen- 


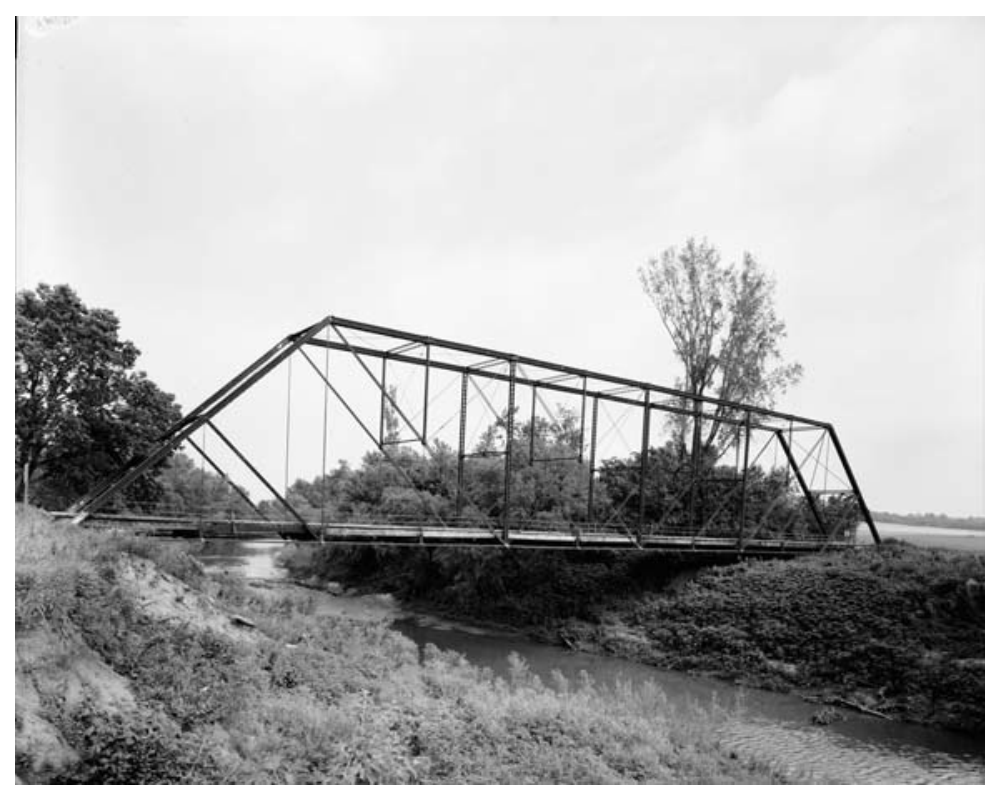

Figura 19. HalfMound Bridge, Spanning Delaware River on Federal Aid Secondary Route 1325, Valley Falls, Jefferson County, KS. Fotos. Library of the Congress. USA. http://loc.gov/pictures/item/ks0048/ te abandonado en favor del hierro y luego del acero. Este proceso se explica claramente en una publicación sobre infraestructuras ferroviarias editada en una fecha tan temprana como 1893:

"El avance desde la celosía de madera hacia la estructura de acero moderna se ha realizado a través de una serie de etapas. Excelentes puentes fueron construidos en combinaciones de madera y hierro, y todavía están indicados en localizaciones donde la madera es barata. Después vino el uso de hierro fundido para aquellas partes de la armadura sujeta únicamente a esfuerzos de compresión y hierro forjado que se utiliza para las barras que trabajan a tracción (...). La forma de esta cercha combinada varía con los diseños de diferentes ingenieros y las luces salvadas se ampliaron a más de 300 pies $(91.44$ $\mathrm{m})$. Las vigas llevaban los nombres de los diseñadores y las vigas Fink, Bollman, Pratt, Whipple, Post, Warren, y otras muchas, tenían cada uno sus defensores y detractores. La sustitución progresiva del hierro fundido por hierro forjado ha continuado y hasta hace muy poco se han utilizado para todas las estructuras de gran envergadura celosías construidas enteramente con este material. El último paso se ha dado con el uso del acero, en un primer momento solo para los miembros especiales de una cercha y, últimamente, para toda la estructura. El arte de la construcción de puentes de ferrocarril por lo tanto, en un tiempo de relativamente pocos años, pasó a través de su edad de la madera, a continuación del hierro, y ahora se basa en el uso de acero en todas sus partes". (VV AA 1893: 85)
De todas las celosías nombradas en la cita, nos interesa especialmente la viga Pratt $^{23}$ por ser éste el tipo de puente que Albert Kahn utilizará para la primera ampliación del edificio de ensamblaje de aeronaves de Glenn L. Martin. Pratt básicamente tomó la viga Howe y sustituyó los elementos diagonales a compresión de madera por dos barras de hierro con roscas y tuercas a tracción (cambiando la dirección de las barras) y mantuvo los montantes verticales a compresión de madera. La otra cercha más popular de la época en la industria del ferrocarril, era la viga Warren (1846), sin verticales y con diagonales alternas a compresión y tracción. Esta es la otra celosía utilizada por Kahn en la fábrica Glenn L. Martin.

Pero todas estas vigas en celosía necesitaban para su construcción del uso de andamiajes de madera bajo el puente. Normalmente estas cimbras se podían situar sobre cimentaciones provisionales o sobre plataformas flotantes. Una vez construido el puente, se dejaba que entrara en carga y se retiraban estos medios auxiliares. Pero había numerosas situaciones topográficas, que hacian imposible la situación de estos andamios o la convertían en tan costosa que era mejor convertir estos andamios en la propia estructura portante de las vias. ${ }^{24}$

La solución de los ingenieros americanos a este problema fue el puente en voladizo. El primer ejemplo de este tipo es el Puente sobre el rio Kentucky, de 1877, en Highbridge, Kentucky (figura 20). ${ }^{25}$ Pero el puente en voladizo que marco esa época es el Puente sobre el río Niágara (figura 21). Nos interesa especialmente por su carácter de paradigma de los puentes en voladizo y por su relación con la trayectoria profesional de Julius Kahn. La importancia del puente se puede demostrar solo citando el congreso monográfico sobre esta construcción celebrado en 1885 en Buffalo por la American Society of Civil Engineers ${ }^{26}$ y la publicación (Schneider 1885) que resulto del mismo.

El puente en voladizo sobre el Niagara, construido en solo 8 meses, era una estructura de 910 pies $(277.37 \mathrm{~m})$ de longitud, que salvaba un vano central de 470 pies $(143.26 \mathrm{~m})$. Se construyó sobre dos soportes con dos vigas en voladizo doble, un voladizo sobre las entregas y otro sobre el vano central en equilibrio. Estos voladizos centrales se unían luego con otra viga que apoyaba en sus dos extremos y que se construyó usando una estructura auxiliar deslizante en los propios vuelos. 

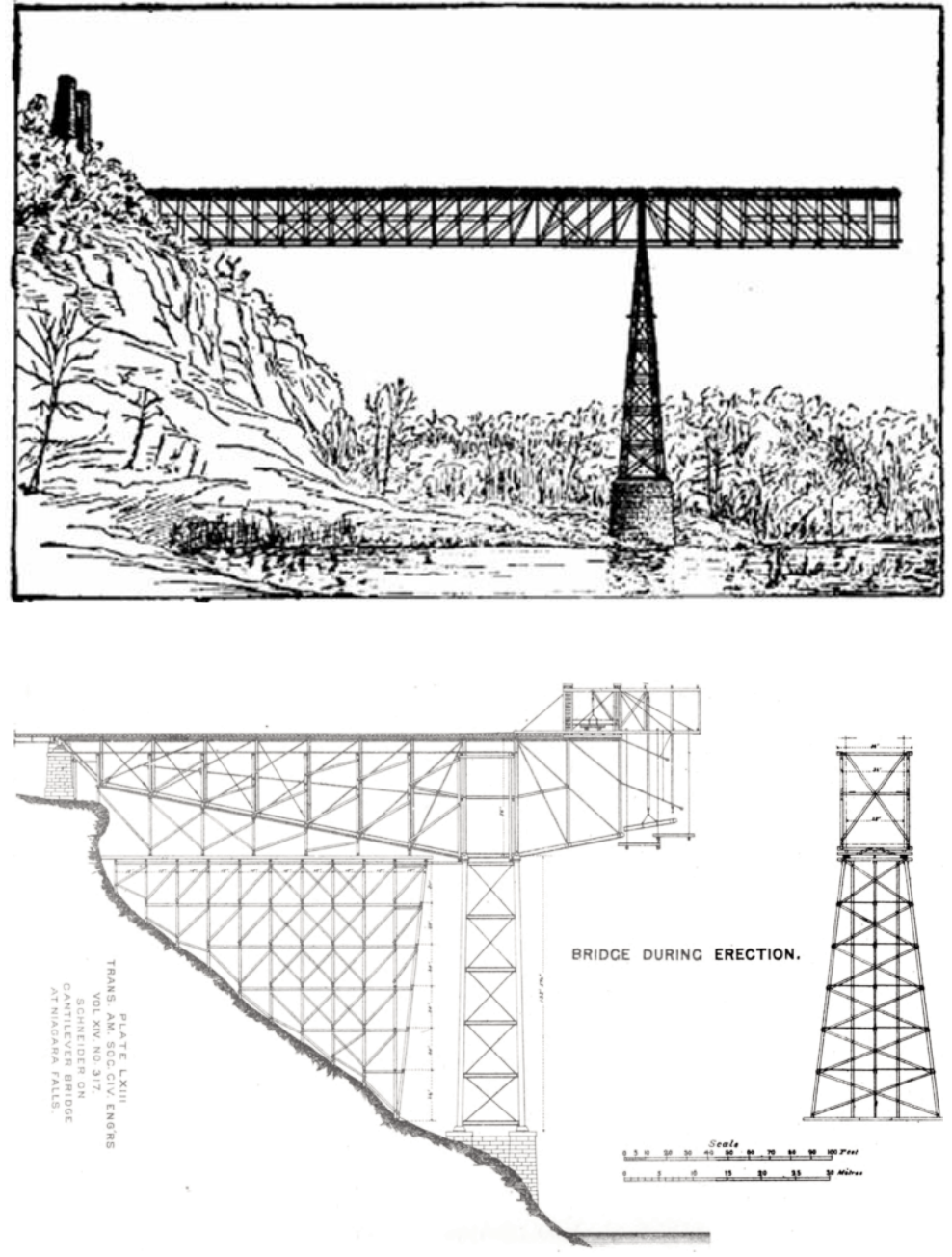

Arriba. Figura 20. Puente en voladizo sobre el Kentuky. (Middleton 1999)

Abajo. Figura 21. Puente en voladizo sobre el Niagara. (Schneider1885)
Por otra parte, cuando se construyó este puente, Schneider era el ingeniero jefe de la empresa adjudicataria del diseño y la construcción, la Central Bridge Company. Esta empresa era la unión de otras dos, la Union Bridge Company y la Morrison-Field Bridge Company. Leyendo una biografia resumida de Julius Kahn (Marquis 1914) podemos ver que después de graduarse en ingeniería civil en 1896 por la Universidad de Michigan, trabajó, además de como ingeniero militar en el ejército, precisamente en la Union Bridge Company. Parece por tanto una hipótesis bastante factible que estuviese perfectamente al corriente de los pormenores del diseño de este puente en particular y de los puentes en voladizo en general.

El siguiente paso de esta investigación será rastrear en la obra de Albert Kahn la presencia de los dispositivos proyectuales provenientes de la ingeniería ferroviaria americana, que en resumen son:

- Edificios paralelos a ambos lados de las vías.

- Lucernarios centrales y laterales.
- Sección escalonada interior y exteriormente.

- Superposición-encabalgamiento estructural.

- Basamento inferior hueco.

- Medios de elevación mecánica.

- Espacio de movimiento de cargas vertical.

- Chimeneas de ventilación y extracción.

- Voladizo como herramienta proyectual.

Se ha revisado anteriormente la relación de la New Shop de Highland Park con el tipo de las freighthouses y las enginehouses. Presentaremos a continuación un conjunto de obras de Kahn, que tienen una notable continuidad de diseño con estas dos familias tipológicas ferroviarias: las forge shops (taller de forja). A partir de la sección de la forge shop de Packard (1911), la más compleja e interesante de todas, repasaremos el uso de vigas de puente biapoyadas en la primera ampliación de la factoría aeronáutica de la compañia Glenn L. Martin de Baltimore (1937) y otros ejemplos como la nave de ensamblaje de aviones de Ford Willow Run en Ypsilanty, Michigan (1941). El uso del voladizo se estudiará a partir de dos proyectos de la última etapa de Kahn, la segunda ampliación de la factoría aeronáutica de la compañía Glenn L. Martin de Baltimore (1939) y la Half Ton Truck Plant de Chrysler (1937).

\section{Conclusiones. Forge shops, vigas puen- te $y$ estructuras en voladizo en Kahn}

Una de las familias de edificios que presenta unos rasgos tipológicamente más homogéneos dentro de la obra industrial de Kahn son las forge shops. ${ }^{27}$ Esta familia tipológica cuenta con un gran número de edificios clónicos. Por ejemplo todas las forge shop de las fábricas soviéticas de los años 1928 al 1932, tienen exactamente la misma disposición y dimensiones en sección, pudiendo variar su longitud en planta de una localización a otra. Las forge shop de la Autostroy Corporation en Cheliabinsk, de la Stalmost Steel Fabricating en Nijni Tagil y de la Amtorg Trading Corporation en Estaligrado, presentan las tres la misma sección consistente en una nave única de 24 metros de anchura total, cubierta con una cercha tipo Warren con una ligera inclinación a dos aguas (figura 22).

Sobre esta estructura primaria hay una estructura encabalgada que forma un lucernario central trapezoidal. Las juntas entre distintas secciones, se resuelven con un detalle que se repetirá sistemáticamente en toda esta familia edificatoria, la 

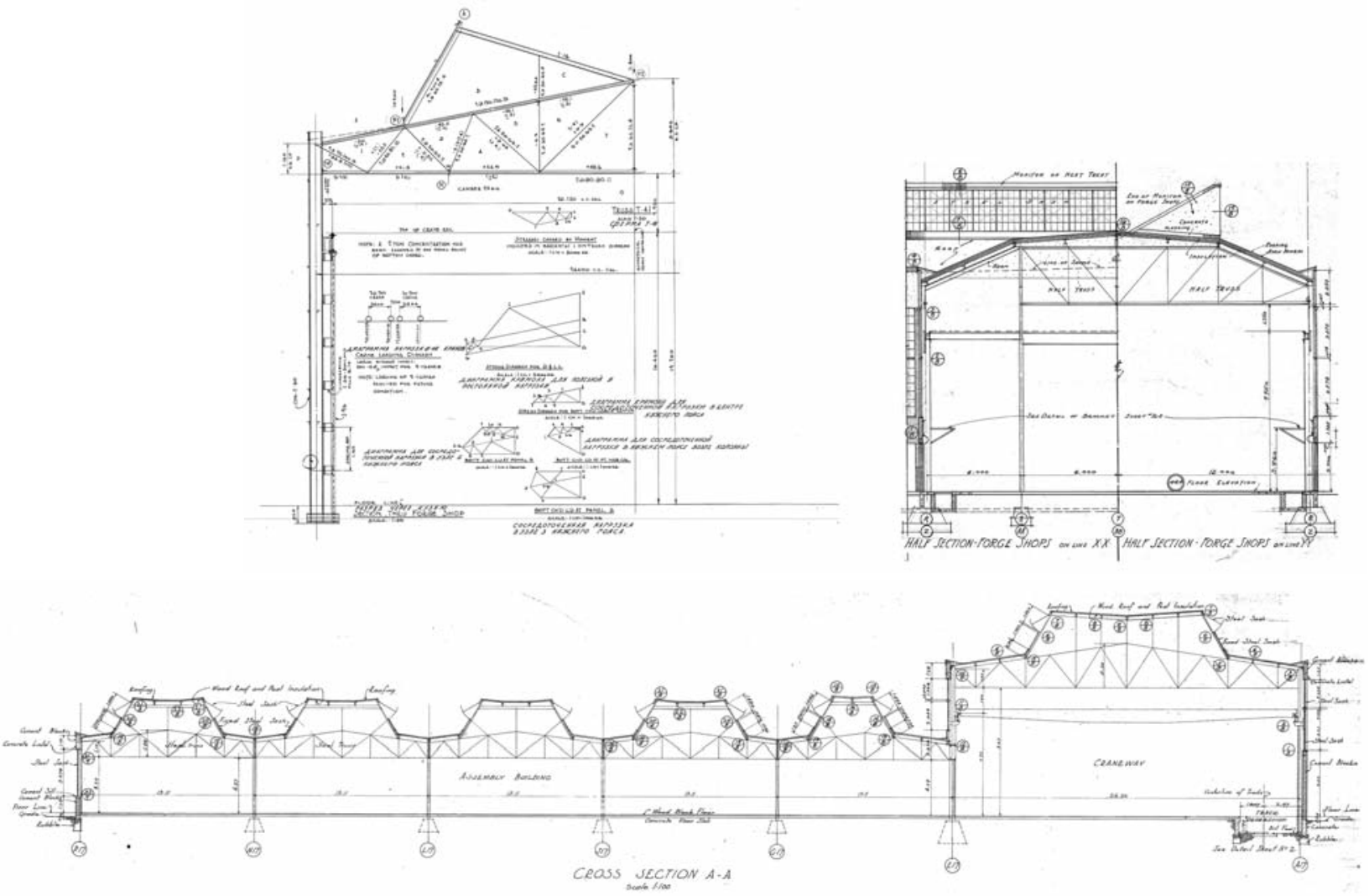

Figura 22. Forge shopsrusas de Autostroy, Stalmost y Amtorg Corporation. Drawer 17 and tube 34. Albert Kahn Papers, Albert Kahn Associates Inc. and the Bentley Historical Library, University of Michigan.

Figura 23. Forge shop de Packard. 1911.

(Ferry1970) junta de acordeón formada por dos placas de acero soldada en ángulo agudo. Estas secciones son perfectamente asimilables a la sección de una primitiva enginehouse o freighthouse ferroviaria de una planta con estructuras encabalgadas para formar tanto lucernario central como laterales. Se forma así una sección escalonada tanto interior como exteriormente, con una parte central más elevada que ayuda a disipar el calor y los gases producidos por la actividad de la forja que se alberga en el interior.

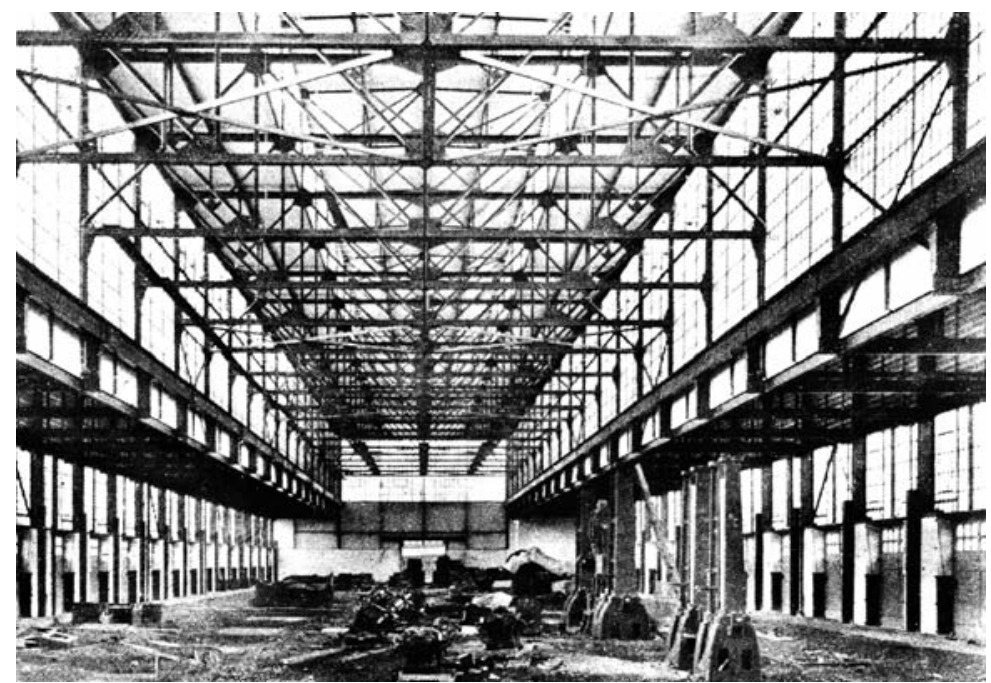

Dentro de esta familia, la forge shop de la compañía Packard en Detroit (figuras 23 y 24) es un ejemplo con un uso más sofisticado de la sección, que implica además la utilización del voladizo estructural como elemento básico de diseño. En la sección de este edificio podemos observar como el origen bien pudiera ser una freighthouse de una planta y sección escalonada. En este caso hay tres niveles estructurales superpuestos: unas cerchas triangulares que conforman los cuerpos bajos, una cercha principal que cubre la luz completa del edificio y un encabalgamiento superior para formar un lucernario central. Pero la estructura del primer nivel, en vez de conformar dos naves laterales adosadas exteriormente al espacio principal, se pliega hacia el interior. Esto hace que estas estructuras que estaban apoyadas en pilares exteriores o en vuelo, en una sección convencional, ahora se encuentren en el interior de la nave principal. En estas estructuras interiores, colgadas de la cercha principal, se apoyan las vías del puente grúa, evitando el uso de pilares que pudieran interferir con las actividades de la forja. La relación de la piel exterior con la estructura en este edificio es extremadamente compleja, apareciendo por primera vez en Kahn el uso de exoestructuras que traspasan el cerramiento exterior y que en este caso, conforman un 


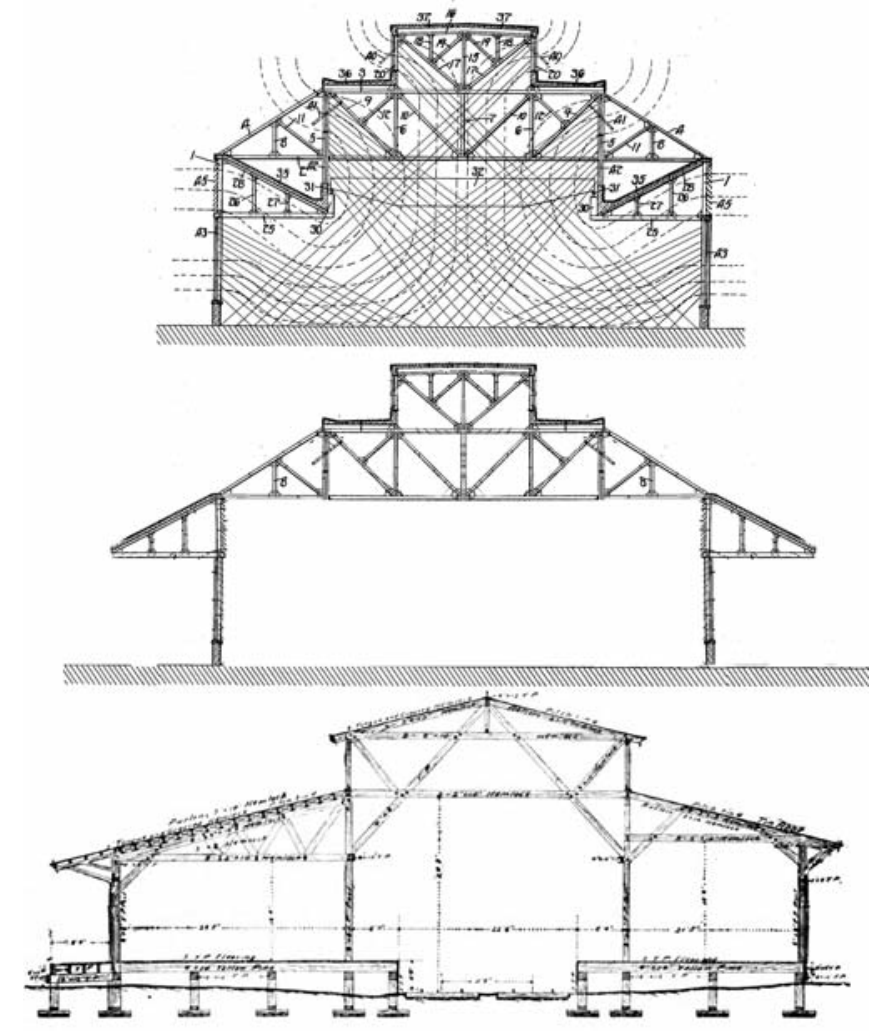

Figura 24. Posible evolución tipológica de la sección de la forge shop de Packard desde la freighthouse escalonada.

Freighthouse de Newark, NJ, de la Leigh Valley Railroad Company 1892. (Berg1900)

Figuras 25 y 26. Half Ton Truck Plant de Chrysler. Albert Kahn 1937. Fotos de obra. Box 4.Albert Kahn Papers, Albert Kahn Associates Inc. and the Bentley Historical Library, University of Michigan. espacio escalonado que en las fotos presenta un aspecto curiosamente similar al de una catedral gótica. La sección de la estación de Meadville (figura 5), también puede resultar una referencia útil para esclarecer el parentesco tipológico de las forge shop. La sección es similar y el tren, en este caso, es sustituido por un mecanismo de funcionamiento análogo; el puente grúa que desliza sobre raíles pero de forma elevada y que cubre todo el espacio central de estas nuevas "estaciones industriales".

Este primitivo uso del voladizo ${ }^{28}$ y de las estructuras de puente en la forge shop de Packard fue seguido en numerosos edificios de Kahn. En general, se usa para aligerar los cantos de las vigas o cerchas de las repetitivas estructuras de las naves de montaje de la industria aeronáutica o automovilística. Hay tres casos de este uso que son especialmente interesantes: la Half Ton Truck Plant de Chrysler y las dos ampliaciones de Glenn L. Martin.

La Half Ton Truck Plant de Chrysler (figuras 25 a 30) consiste en dos edificios: en la parte norte, una nave de ensamblaje de $402 \times 1262$ pies (122.5x384.6 metros) y en el Sur, el Export Building de 122x242 pies (37.5x73.8 metros). Ambos están compuestos por el mismo tipo de sección, pero mientras en el Export Building está apoyada en la línea de cerramiento al ser una sección única, en la nave de ensamblaje se multiplica horizontalmente y usa el voladizo como conexión entre secciones. El edificio de ensamblaje está en realidad compuesto de tres partes: una banda de oficinas de dos plantas en el Oeste; un edificio de más altura, con entreplantas en algunas partes, situado en el Norte y que servía para almacenaje y entrada y salida de materiales; El edificio principal es en cambio una repetición de las secciones del Export Building invertidas. La estructura está compuesta en un sentido por cerchas y en el otro por vigas en doble $\mathrm{T}$ de alma llena de acero cada 20 pies $(6.10 \mathrm{~m})$, unas coincidiendo con el pilar y otras en el punto medio del vano de la cercha. Las cerchas se apoyan cada 40 pies (12.20) y están separadas 60 pies $(18.30$ $\mathrm{m})$ unas de otras. Kahn consigue, mediante el voladizo, reducir el canto de las vigas al que se necesitaria para una luz de 30 pies $(9.15 \mathrm{~m})$ si estuvieran biapoyadas. Las vigas de alma llena descansan sobre la cercha y salvan los 60 pies (18.30) de luz libre, volando 12 pies $(3.66 \mathrm{~m})$ a cada lado. Estos vuelos soportan un lucernario rehundido del nivel de cubierta en vez de elevado y, se completan con un tramo de viga horizontal. Estos lucernarios "colgados" aumentan la cantidad de iluminación que llega al nivel del suelo y llamaron la
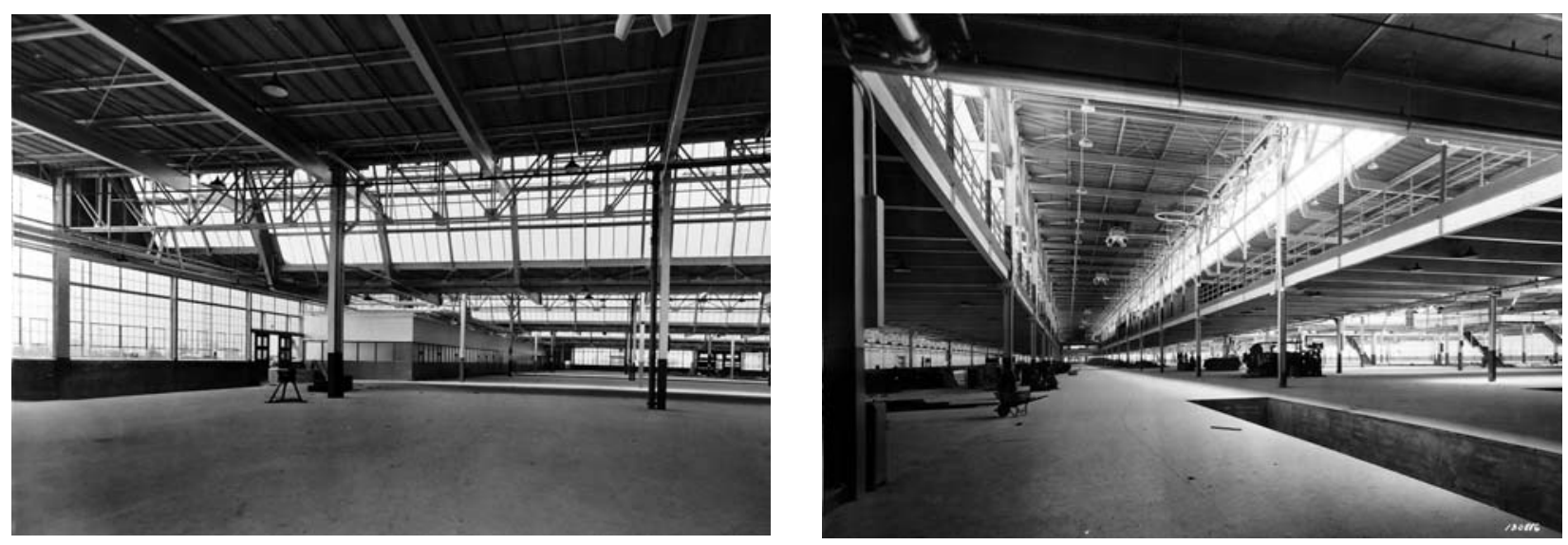


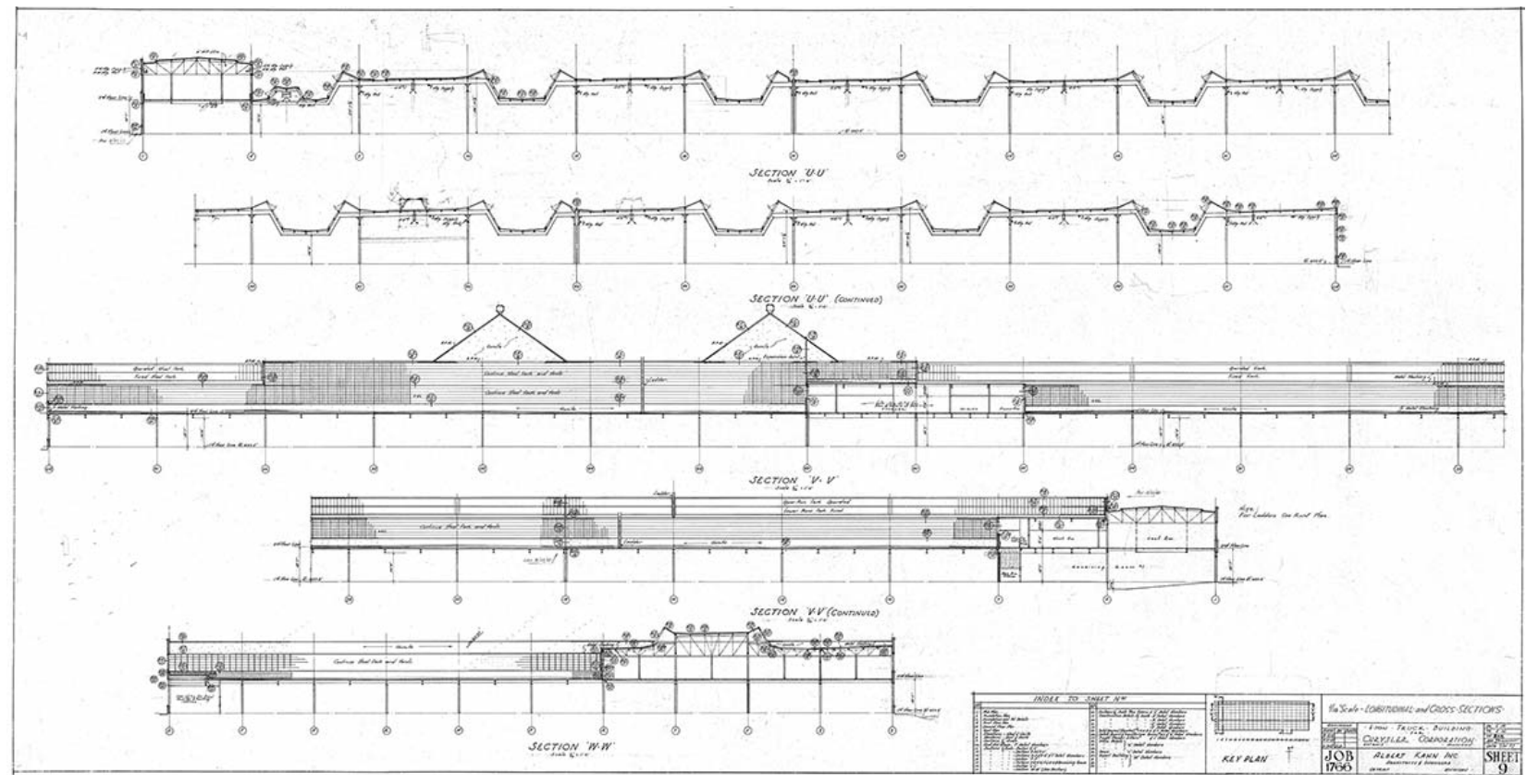

Figuras 27 y 28.

Half Ton Truck Plant

de Chrysler. Albert

Kahn 1937. Planos de

estructura. Tube 65.

Albert Kahn Papers,

Albert Kahn

Associates Inc. and

the Bentley Historical

Library, University of

Michigan.

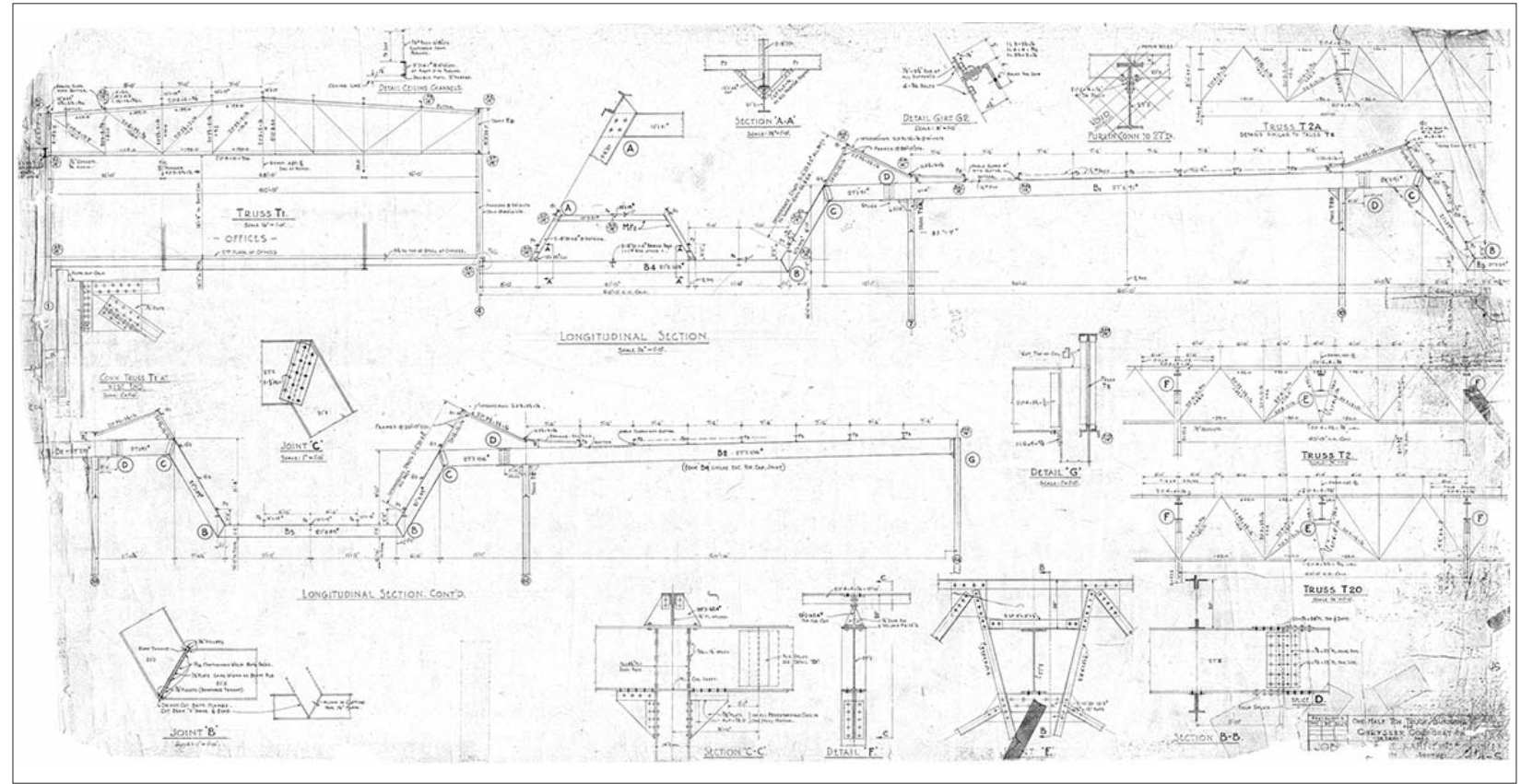




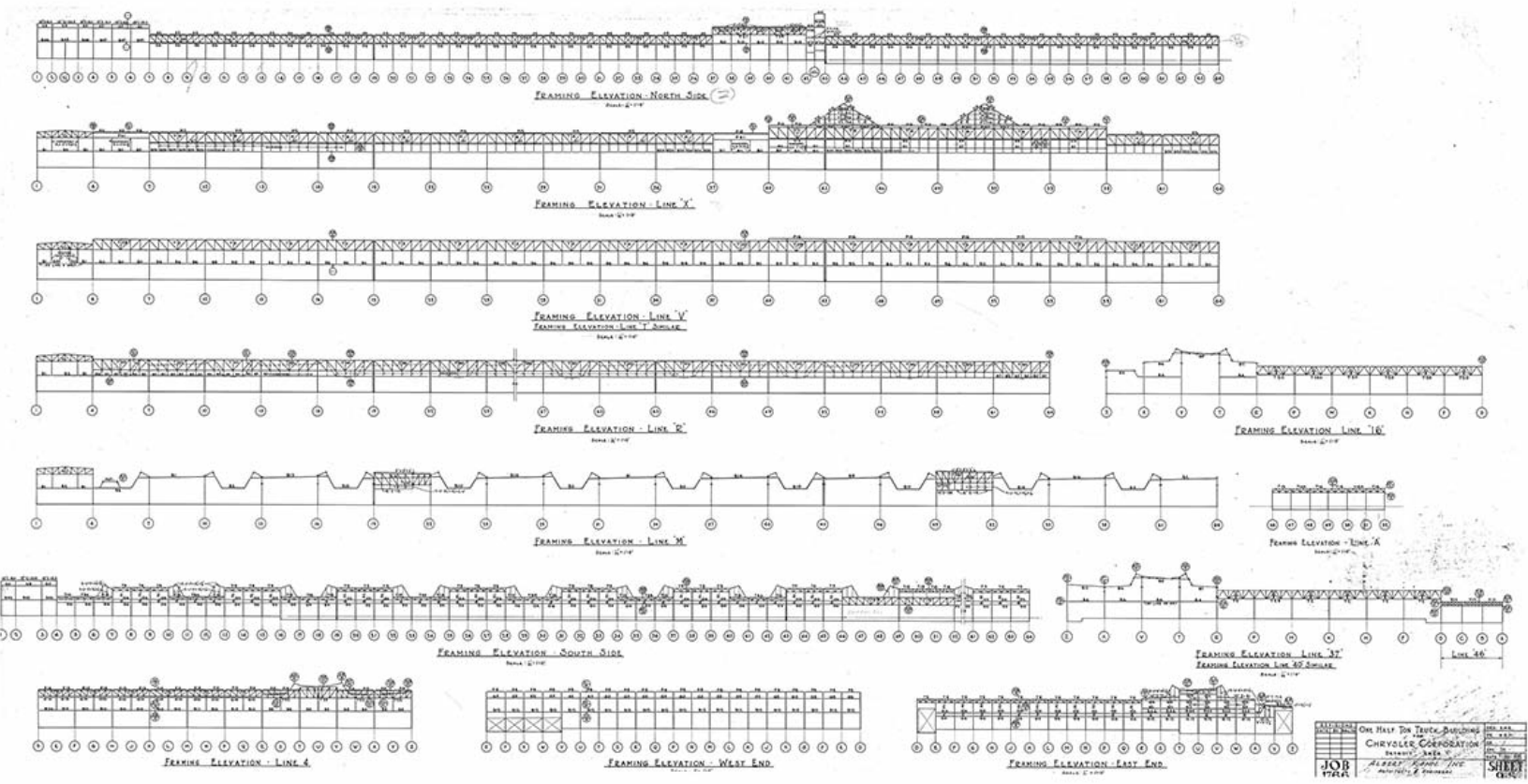

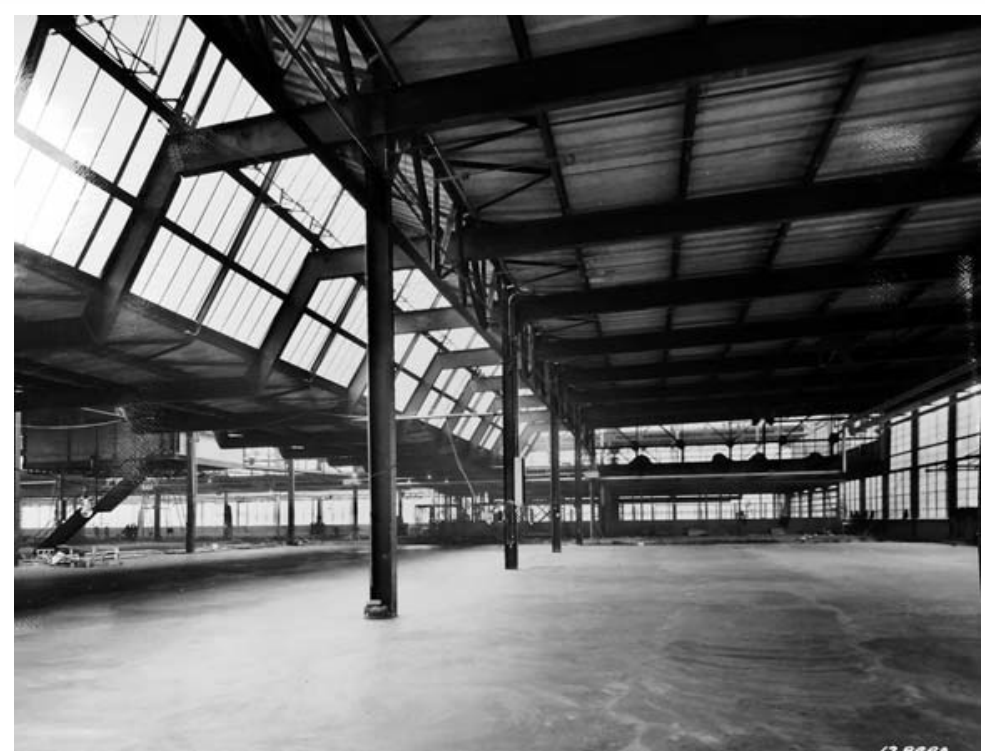

Figuras 29 y 30. Half Ton Truck Plant de Chrysler. Albert Kahn 1937. Planos de estructura e imagen interior. Tube 65. Albert Kahn Papers, Albert Kahn Associates Inc. and the Bentley Historical Library, University of Michigan. atención incluso del presidente de la compañía Chrysler, K. T. Keller que llegó a decir que "el tejado del edificio se había construido al revés" (Nelson 1938: 84). Así, la nave principal de ensamblaje estaba compuesta por bandas elevadas sin lucernario de 29 pies y 7 pulgadas $(9.02$ $\mathrm{m})$ de altura libre y bandas bajas con lucernario de 16 pies $(4.88 \mathrm{~m})$ de altura libre. Es un uso del voladizo similar al que hemos visto con anterioridad en las trainsheds de múltiples luces, como la North Station de Boston, por su masiva agrupación horizontal, y la enginehouse en East Mauch Chunk, en la que el voladizo era una estrategia repetida en cada módulo estructural para producir los espacios de los andenes de reparación. Pero es espe- cialmente evidente la relación tipológica que esta estructura tiene con ejemplos como las estaciones centrales de Nueva Orleans y de Chicago.

El segundo caso de estudio de este apartado es doble. Son dos sucesivas ampliaciones de la misma nave de ensamblaje para aviones Glenn L. Martin, en Baltimore en los años 1937 y 1939. La primera ampliación (figuras 31 a 39) supuso un importante reto estructural, ya que se trataba de construir un espacio diáfano de $300 \times 450$ pies $(91.44 \times 137.16$ metros $)$ en planta. Uno de los laterales de esta enorme nave debía poder ser abierto completamente mediante algún sistema de puertas o paneles móviles. En el estudio de Kahn se realizó un concurso interno para este proyecto. Se eligió el diseño que tenía el menor peso de acero por metro cuadrado de cubierta, formado por vigas Pratt de 300 pies $(91.44 \mathrm{~m})$ de luz y 30 pies (9.14) de canto. ${ }^{29}$ Estas vigas puente de tipo Pratt, se unen alternativamente por una plataforma superior o inferior formada por vigas Warren ${ }^{30}$ que cubrian los 50 pies $(15.24 \mathrm{~m})$ entre cerchas.

Esta duplicación permite leer la estructura como si estuviera conformaba por una serie de 5 puentes de tipo poney invertido que sustentan una cubierta baja entre cada dos de ellos. En esta estructura no se hizo uso del voladizo, sino de la viga en cajón biapoyada típica de los primeros puentes americanos construidos en hierro. En cambio, si nos fijamos en las fotos 


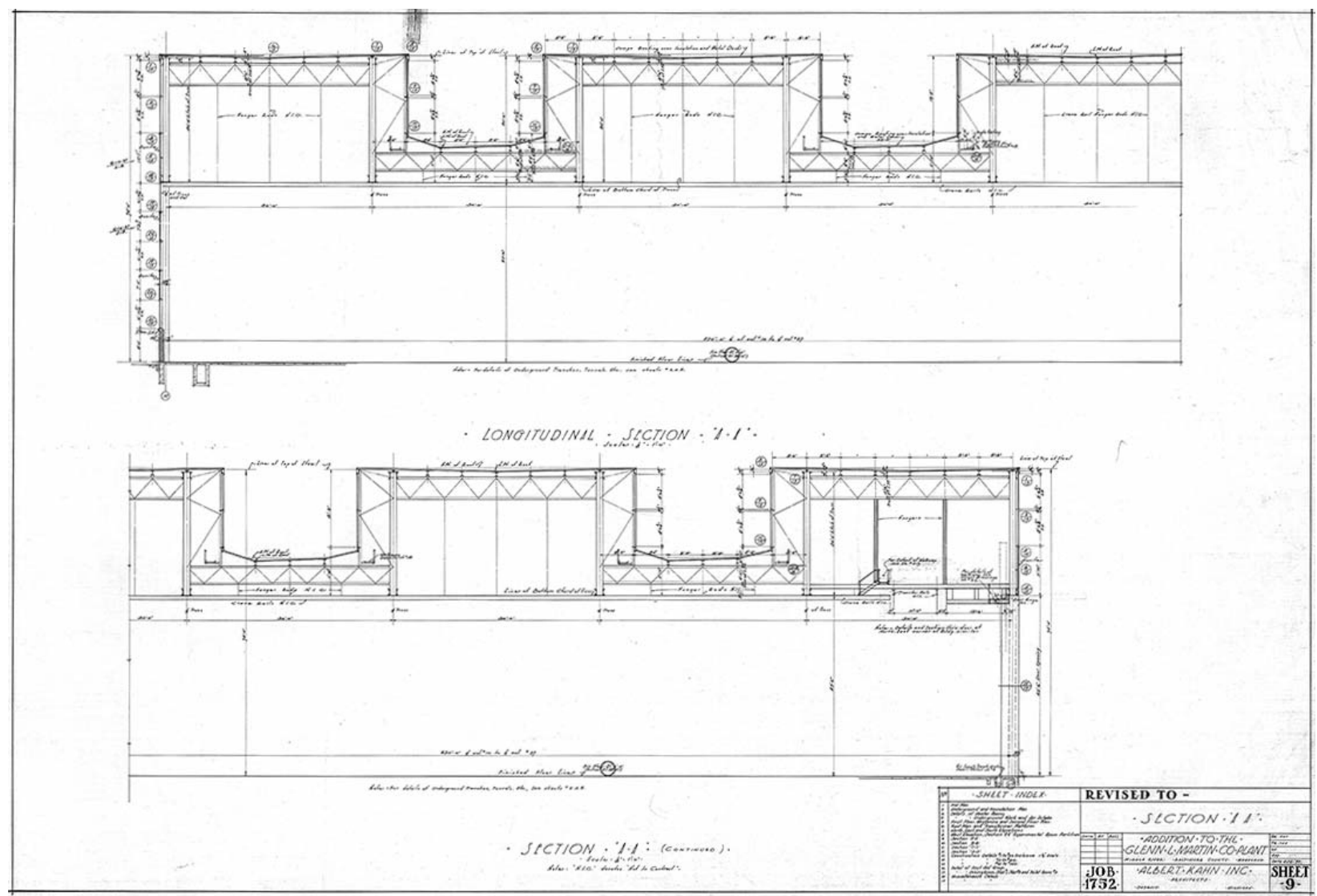

Esta página y siguiente. Figuras 31 a 34. Primera ampliación de Glenn L. Martin Co. Assembly Building. 1937. Planos de estructuras. Drawer 16 y tubes 31, 32 y 33. Albert Kahn Papers, Albert Kahn Associates Inc. and the Bentley Historical Library, University of Michigan.

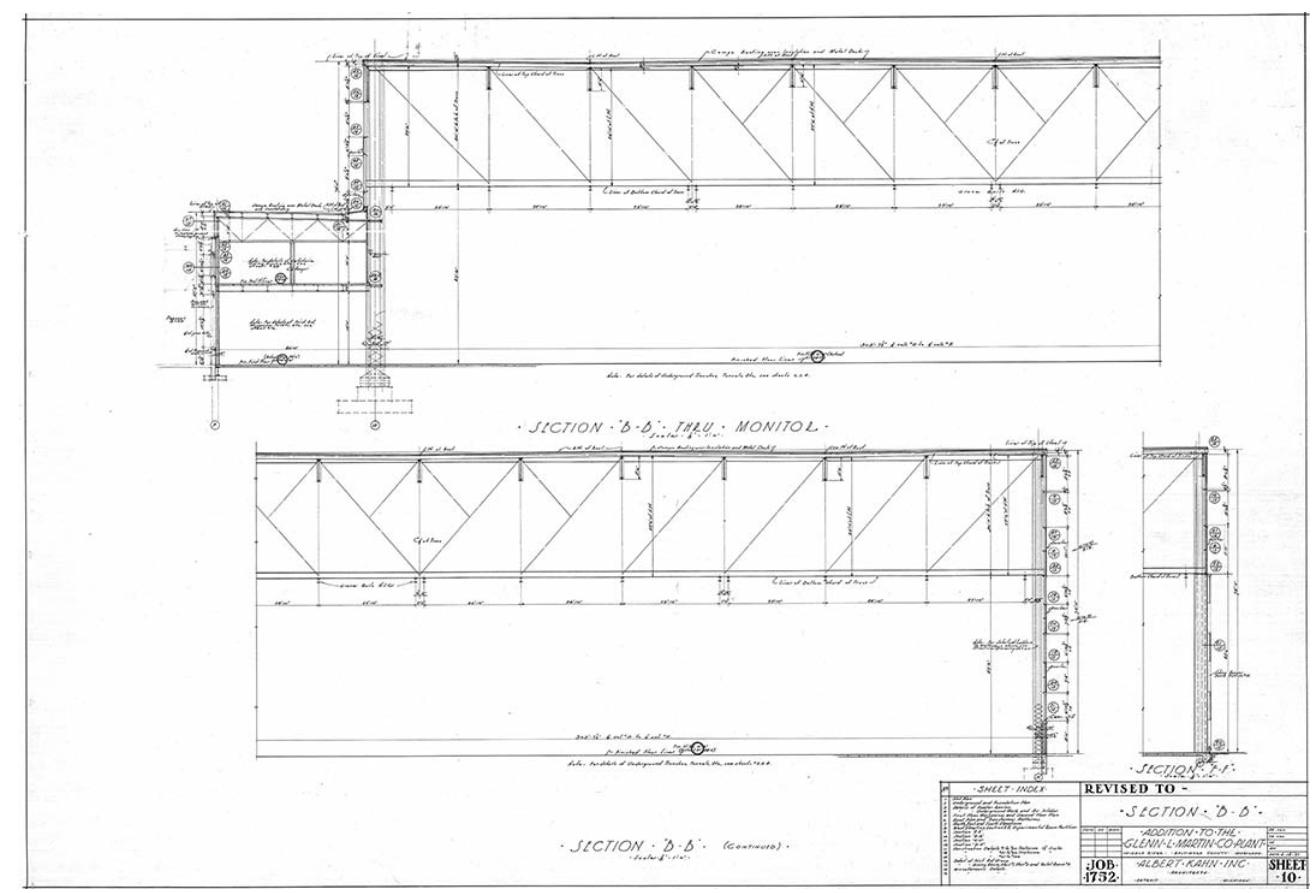



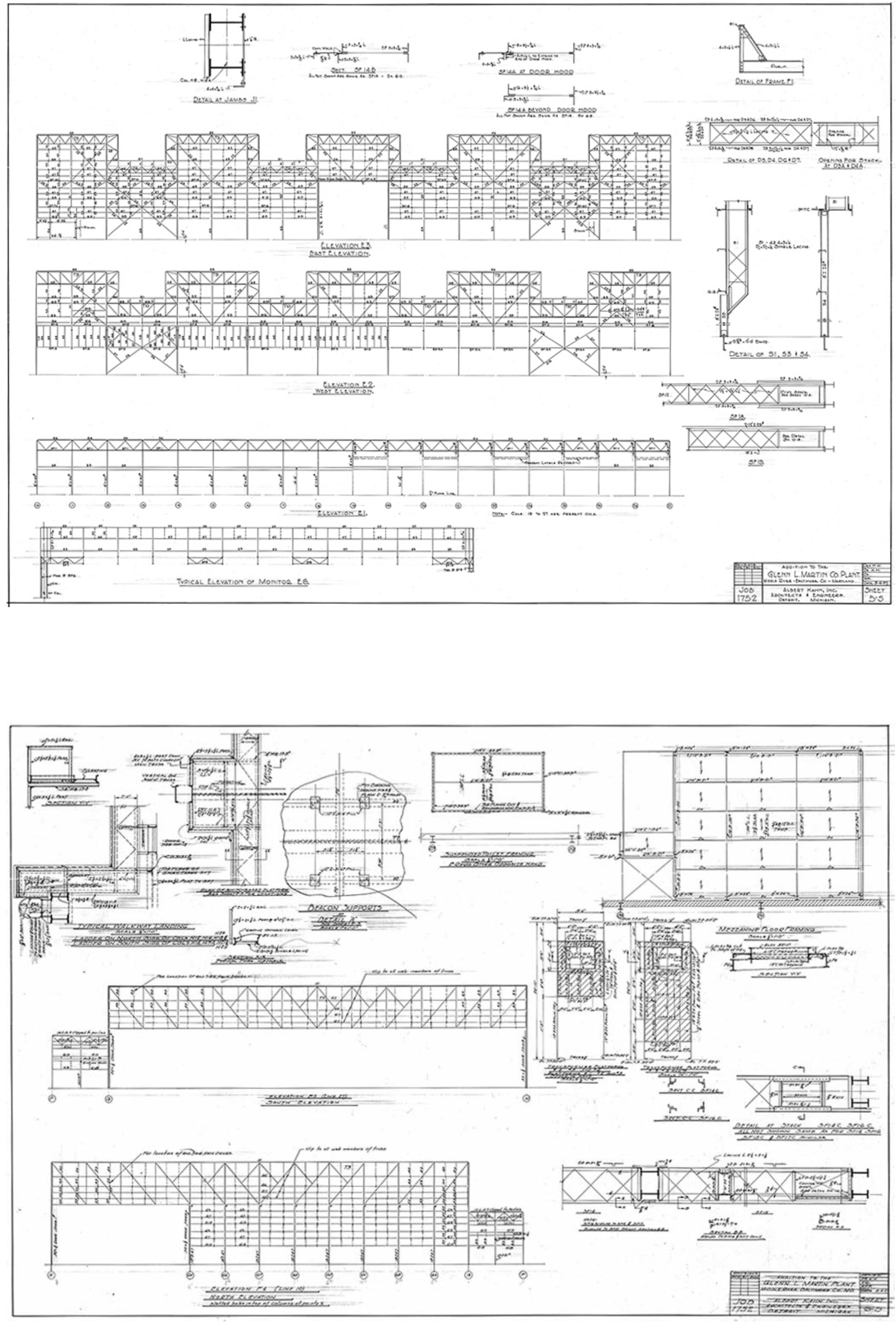

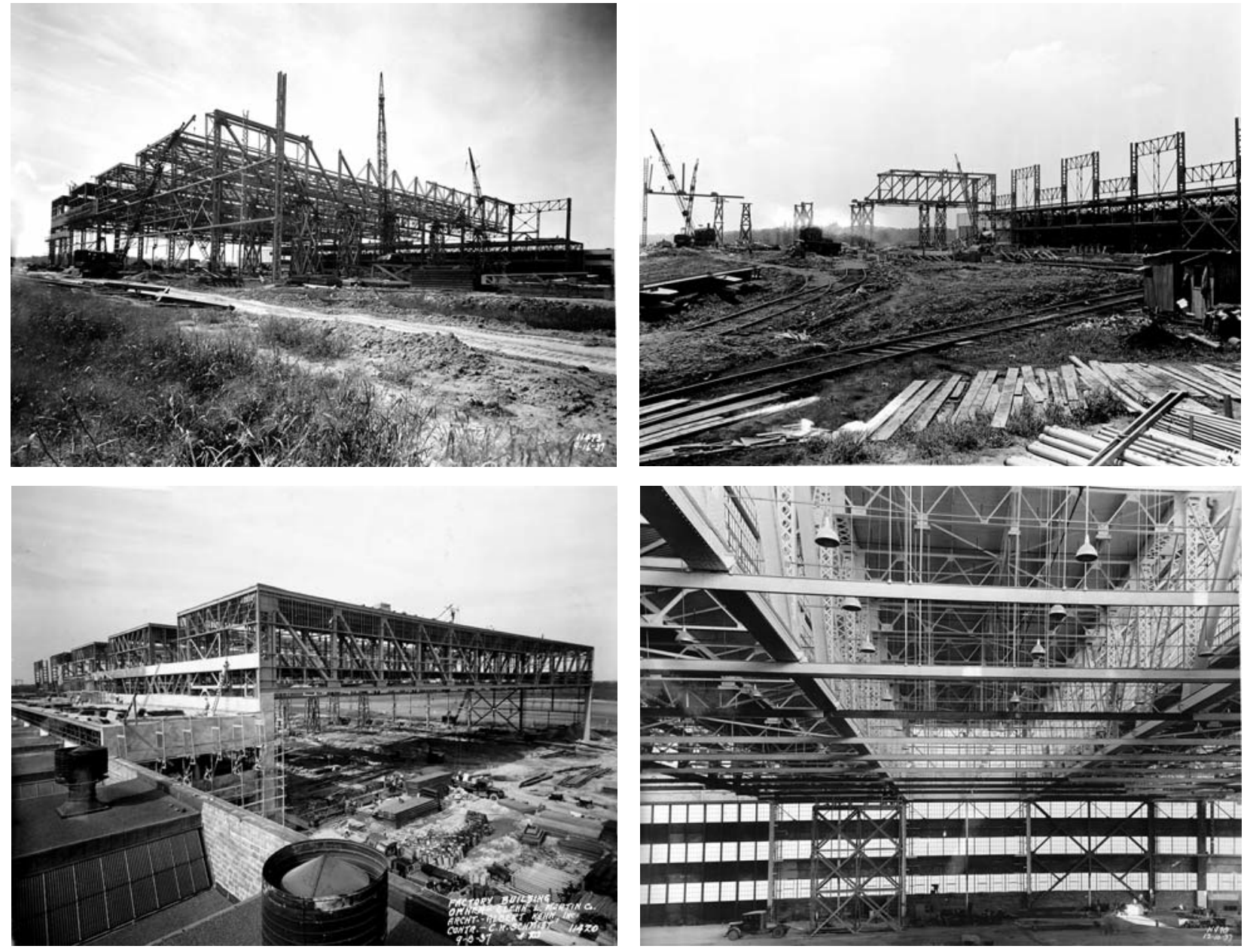

Esta página. Figuras 35 a 39. Primera ampliación de Glenn L. Martin Co.

Assembly Building. 1937. Fotos de obra. Box 4. Albert Kahn Papers, Albert Kahn Associates Inc. and the Bentley Historical Library, University of Michigan.

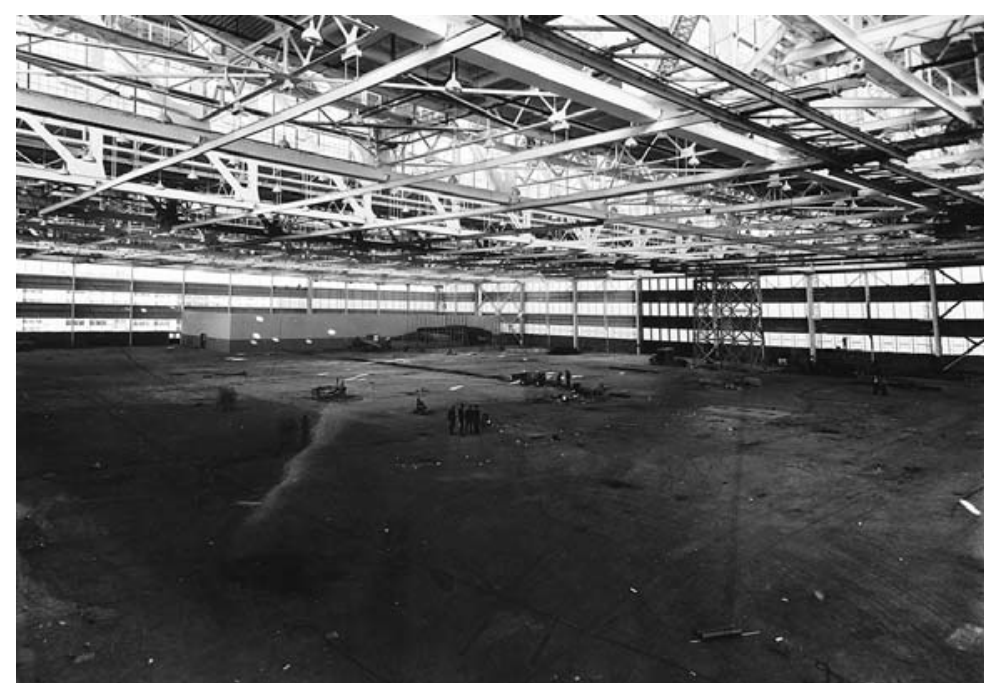

parte cercana al cordón inferior para evitar pandeo local y flexión en los elementos más largos. ${ }^{31}$

La segunda ampliación de la Glenn L. Martin (figuras 40 y 41) surge de una llamada telefónica. En ella se pide a Albert Kahn que diseñe y construya la segunda ampliación de la fábrica en un plazo de 84 dias (desde el 5 de febrero en que recibe la llamada al 1 de mayo de 1939, en que la fábrica debía estar operativa para contribuir al esfuerzo de guerra de la Segunda Guerra Mundial). Kahn planeó un basamento de hormigón hasta la primera planta (para ahorrar tiempo, puesto que había una contrata de hormigón operando en la fábrica en ese momento). Los trabajos de hormigón empezaron en 11 días. El edificio se acabó el 23 de abril de 1939 y la producción de aviones empezó tres días después. Kahn repetiría exactamente las mismas estructuras de ambas ampliaciones cuando tuvo que construir las fábricas para Glenn L. Martin de Middle River, Maryland, y en Omaha, Nebraska, en un rasgo muy característico de su actividad profesional. 
Figuras 40 y 41 . Segunda ampliación del Glenn L. Martin Co. Assembly Building. 1939. Box 4. Albert Kahn Papers, Albert Kahn Associates Inc. and the Bentley Historical Library, University of Michigan.
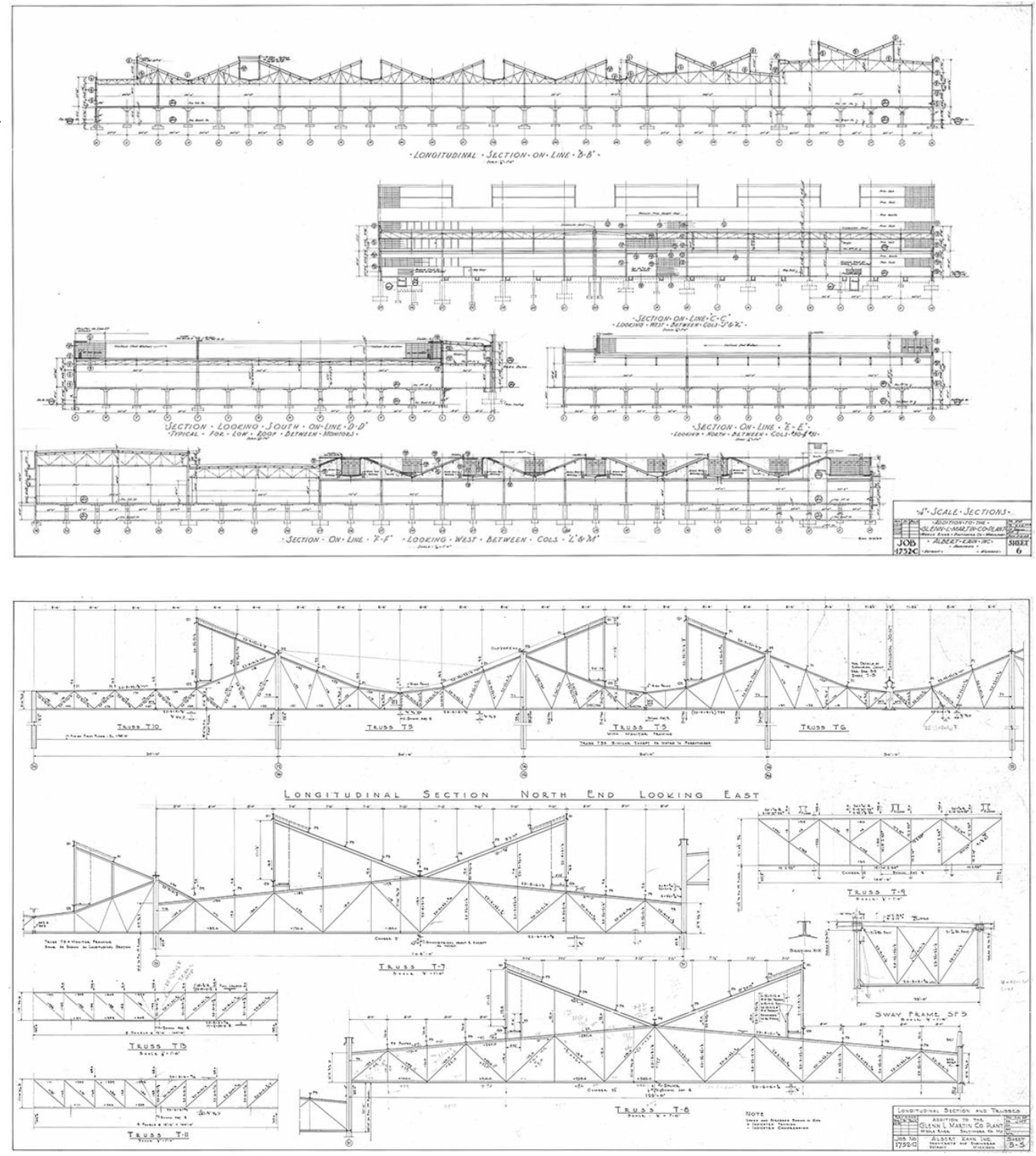

La estructura del edificio tiene una vez más mucha más relación con la ingeniería de puentes que con la construcción convencional. El módulo estructural repetido, esta vez, es un doble "voladizo" de cerchas Warren con el cordón superior inclinado formando un lucernario lateral. Se agrupan de forma simétrica, formando un tejado bajo entre dos lucernarios laterales. La luz en la dirección perpendicular a las cerchas principales se cubre con vigas Pratt rectas. La solución es coincidente con las adoptadas en las infraestructuras ferroviarias en el uso de basamento de comunicación, (en este caso para instalaciones), en el uso del voladizo estructural, en la sección escalonada, y en la superposición de estructuras formando lucernarios. Podríamos decir que es una combinación de una multiple trainshed con una estructura de puentes en voladizo. Hildebrand (1974) hace una valoración de estas dos ampliaciones que las relaciona claramente con la ingeniería de obras públicas más que con la arquitectura y que parece hecha para apoyar la tesis principal de este artículo:

"La planta completa es uno de los mejores diseños de Kahn. Aunque más pequeño que muchos otros, aquí trata con la fabricación de máquinas a una escala sin precedentes, incluso en su propia obra. Los principios detrás de cada aspecto del diseño son conservadores; el poder de las soluciones reside en la explotación de estos principios a una escala y con una audacia que normalmente se encuentran sólo en las grandes obras de ingeniería civil, de la que, de hecho, se extrajeron esos principios". (Hildebrand 1974: 197).

Podemos por tanto concluir en que hay una serie muy numerosa de obras de Kahn que presentan características que 
las ligan fuertemente a ciertas familias tipológicas provenientes de la ingeniería ferroviaria americana. El caso de la New Shop de Highland Park, es extremadamente claro, pues incluso tiene descendientes tipológicos que se reinsertan en el tipo inicial como la freighthouse del Navy Yard de Brooklyn. Esto, junto con otros datos como el trabajo de Julius Kahn en empresas de este sector, nos permite resituar la figura de Kahn dentro de la ingeniería ferroviaria americana de finales del siglo XIX. Es el uso de herramientas obtenidas en esta tradición, lo que permite a Kahn llegar a soluciones realmente novedosas que supusieron una influencia central para la arquitectura moderna del nacimiento del siglo XX. Por medio de esta influencia, Kahn se convierte en el transmisor de la tradición de la ingeniería ferroviaria a una profesión arquitectónica que, leyendo a Le Corbusier, parece más que dispuesta a aceptarla:

"Estética del ingeniero, Arquitectura, dos entes solidarios, consecutivos, el uno en pleno desarrollo, el otro en penosa regresión. El ingeniero, inspirado por la ley de la economía, y llevado por el cálculo, nos pone de acuerdo con las leyes del universo. Logra la armonía (...) Los ingenieros hacen arquitectura, porque emplean el cálculo surgido de las leyes de la naturaleza, y sus obras nos hacen sentir la ARMONÍA". (Le Corbusier 2006)

\section{Notas}

1. El más importante a nuestro entender es (Hounshell 1984). Para la relación con la arquitectura, ver Hyde (1996).

2. Todas estas actividades listadas por David E. Nye (2013: 17)

3. El inventor de este sistema fue T. Morrison. La patente del invento se puede encontrar en U.S. Patent n. 92.083, Hog Weighing Apparatus, 29 June 1869.

4. Existe un catálogo del trabajo de esta compañía en el que se puede identificar claramente la conexión con el mundo de la ingeniería ferroviaria (C. H. Hunt Company 1893).

5. Herramientas explicadas en profundidad en Borie, Micheloni y Pinon (1978).

6. El estudio de los precedentes de cada uno de estos elementos constitutivos del ferrocarril es interesante. Las vias tendrian su origen en la poliorcética asiria y en la minería del siglo XVI y la tracción mecánica derivaría de una numerosa serie de vehículos experimentales (Lee 1943).

7. Realizada por Cesar Daly, editor de la Revue Generale de L'Architecture.

8. Propiedad de Atlantic and Great Western Depot (1862)

9. Propiedad de Union Depot. (1862).

10. (1883-85) Propiedad de la Chicago and Western Indiana Railroad. Demolida en mayo de 1976 (Hugel 1938).

11. Realizada por Bandford Gilbert, arquitecto, $\mathrm{y}$ J.F. Wallace, ingeniero.

12. Obra de este mismo ingeniero (F. Wallace, Chief
Engineer, Illinois Central Railroad).

13. En ella operaban diariamente 569 trenes, cubría una superficie de aproximadamente 4 acres, con 10 plataformas y 23 vias, con unas dimensiones de 491 pies y 8 pulgadas ( $149.86 \mathrm{~m}$ ) de largo y, 339 y 352 pies respectivamente en el acceso y en la llegada a la estación (103.33 y 107.29 metros). Los arquitectos fueron Shepley, Rutan y Coolidge y el ingeniero, Edward S. Shaw.

14. Propiedad de Pennsylvania Railroad.

15. Propiedad de Leight Valley Railroad Company y diseñada por el propio Walter Berg.

16. Propiedad de Leigh Valley Railroad Company (1892)

17. Propiedad de Leigh Valley Railroad Company.

18. Existen numerosos ejemplos de este mismo tipo de Freight house de dos plantas, como la de Harsimus Cove, Jersey City de la Pennsylvania Railroad, el Grand Street Pier, en la misma ciudad y de la misma compañía o el Freight Pier en Weehawken, Nueva York, de la Lake Erie \& Western Railroad.

19. Los ingenieros Turner y Crocker y el arquitecto Cass Gilbert.

20. Según cuentan Christen y Flanders (2001: 171), para tratar de solventar el problema de los medios mecanizados de carga y descarga, el presidente de la Warboard of the Port of New York, Irving T. Bush, contactó en enero de 1918 con Ford para pedirle que uno de sus ingenieros asesorase a los ingenieros y arquitecto del proyecto. Este asesoramiento se hizo efectivo en mayo del mismo año.

21. Por supuesto, en otros ámbitos territoriales existen precedentes de esta utilización del puente grúa en un espacio vertical iluminado cenitalmente. Por ejemplo, el almacén de barcos de Sheernes en Kent, Reino Unido, de 1858. Pero su lejanía geográfica y el hecho de que el primer viaje documentado de Albert Kahn a Inglaterra sea realizado en 1920 (posterior a la construcción de la fábrica de Highland Park) y restringido a la ciudad de Londres (VV. AA 1972: 33), hacen altamente improbable una influencia directa de este edificio sobre la obra de Kahn.

22. Recopiladas en la publicación sobre puentes de Kemp (2005).

23. Oficina de Patentes de los Estados Unidos de América. Patente número 3,523, del 4 de Abril, 1844 para un Truss frame of bridges (Truss Bridge).

24. Es el caso de los típicos Wooden Trestle Bridges americanos. El mejor estudio sobre ellos es el de Foster (1908).

25. Propiedad de la Cincinnati Southern Railroad Co. El diseño corrió a cargo de Charles Shaler Smith (1836-1886) de la firma Smith, Latrobe \& Company de Baltimore que por aquel entonces habia cambiado su nombre a Baltimore Bridge Company. Este puente, construido en 1876-77, fue el más alto del mundo durante algunos meses, y el primero en ser construido enteramente en hierro forjado. El sistema de voladizos fue adoptado al tener que salvar una garganta de más de 275 pies $(83.82 \mathrm{~m}$ ) de profundidad y con severas y periódicas crecidas torrenciales, por lo que era imposible el uso de andamios. El diseño contemplaba dos tramos laterales construidos en voladizo sobre un solo apoyo temporal. Cuando estos voladizos alcanzaron el apoyo definitivo, el resto del puente se construyó, volando desde estos apoyos hasta encontrarse en el centro, apoyándose en el propio puente sin necesidad de andamios. El puente resultante, después de su construcción y de entrar en carga, consistía en una viga continua con dos apoyos centrales y dos entregas laterales. Además de este, construyeron otros puentes en voladizo como los de St. Paul sobre el Mississippi y el de Montreal sobre el rio St. Lawrence (Middleton 1999: 21).

26. El autor del puente es Charles Conrad Schnei- 
der, americano, nacido en Alemania. 1843-1916. Schneider fue uno de los ingenieros que estuvieron involucrados en la construcción de la Estatua de la Libertad. Entre otros puentes, diseñó también el Puente sobre el rio Fraser de la Canadian Pacific Railway y el puente Longteng en Taiwan en 1906. En 1905 Schneider fue nombrado presidente de la American Society of Civil Engineers.

27. En estos edificios industriales se lleva a cabo el procesado de metales mediante calentamiento. En este proceso se da forma al metal para poder ser utilizado en posteriores procesos de montaje, mediante diferentes medios mecánicos (estiramiento, prensado, enrollado) mediante troqueles, matrices, moldes y prensas. La forja se realiza calentando el metal a temperaturas entre 800 y $1000{ }^{\circ} \mathrm{C}$, por lo que las condiciones de disipación de calor y ventilación son prioritarias junto con la iluminación homogénea de los locales. La presencia invariable del puente grúa en las forge shop de Kahn, añade un elemento móvil más al proceso de forja.

28. El uso del voladizo, tanto en la forge shop de Packard como en la Half Ton Truck Plant de Chrysler, puede revestir un carácter polémico si se consideran como criterios de análisis exclusivamente el comportamiento puramente estructural de las vigas y el estado final del edificio construido. En este artículo, se ha insistido desde el primer momento en dos consideraciones importantes respecto a este tipo de estructuras y respecto a su posible evolución desde precedentes ferroviarios. La primera consideración se refiere al carácter tipológico de esta evolución, que se basa en la persistencia de estructuras formales esenciales, de carácter conceptual, sin suponer necesariamente una persistencia de elementos funcionales, programáticos, fisonómico o en este caso de tipo estáticoestructural. Asi, planteamos la hipótesis de que la estructura de la forge shop de Packard es un derivado tipológico del voladizo aunque la estructura resultante no funcione estructuralmente como tal. De esta misma manera podemos incluir al cine dentro de una familia tipológica que engloba elementos tan dispares como el ferrocarril, los puentes grúa o a la propia cadena de montaje fordista. Por otra parte, en el artículo se ha estudiado el uso del voladizo como una herramienta de proyecto utilizada en etapas intermedias de la construcción de infraestructuras y edificios, aunque estos voladizos no persistan una vez terminada la construcción de la estructura. Esta herramienta se utiliza en estas etapas intermedias para hacer viable el propio proceso constructivo (como en el caso de los puentes en voladizo) o para acelerarlo o abaratarlo (como en el caso de las naves de Kahn). Por este motivo hemos intentado que las figuras del artículo ilustren etapas intermedias de la construcción de estas estructuras, en las que el voladizo se hace evidente. Hay que destacar que muchas de estas construcciones en las que el uso del voladizo resulta ventajoso durante su construcción, tienen el funcionamiento estructural final de una viga continua. Este es el caso de los llamados "puentes en voladizo" y de la Half Ton Truck Plant de Kahn. A pesar de que en este último edificio, el uso del voladizo durante la construcción queda enmascarado por el funcionamiento estructural definitivo, es clarificador ver que este uso es destacado por todos y cada uno de los trabajos previos consultados sobre esta obra de Albert Kahn: Nelson (1939: 84), Hildebrand (1974: 173), Ferry (1970: 24) y Bucci (2002: 79).

29. No habia precedentes de un edificio con una cercha que cubriera 300 metros. Hildebrand ofrece en su monografia sobre Kahn el precedente de la nave de 240 pies $(73.15 \mathrm{~m})$ de la Crucible Steel Mill Company en Harrison, de 1911 y precisa- mente de los train sheds ferroviarios de la década de 1890 con luces de 200 pies $(60.95 \mathrm{~m})$ o la Trainshed de Broad Street en Philadelphia con 300 pies y 8 pulgadas $(91.64 \mathrm{~m})$ en arco. Hildebrand también reconoce que habian sido construidos con anterioridad puentes ferroviarios con mayor luz y da un ejemplo: el puente de la Chicago and Alton Railroad company en Glasgow, Missouri, de 214 pies $(65.23 \mathrm{~m})$ (Hildebrand 1974: 183-184).

30. Las vigas que aparecen dibujadas en los planos son vigas Warren, pero en las fotos de la obra se observa que al menos las de los extremos se ejecutaron también con las diagonales a tracción siguiendo el esquema de las vigas Pratt principales.

31. Un ejemplo similar es el Loosveldt Bridge de 1888 , con refuerzos diagonales en la parte superior de la viga. Otro ejemplo de viga similar es el Half-Mound Bridge, que cruza el rio Delaware en la Federal Aid Secondary Route 1325, Valley Falls, Jefferson County, Kansas.

\section{Bibliografia}

Allison, Tim. 2014. Freight-handling technologies and industrial building design: Freighthouse and warehouse facilities of the Chicago Junction Railway, 1900-30. Industrial Archaeology Review. 36, 2: 109,127.

Banham, Reyner. 1986. A Concrete Atlantis. U.S. Industrial Building and European Modern Architecture 1900-1925. Cambridge: The MIT Press.

Berg, Walter Gilman. 1893. Buildings and structures of American railroads: A reference book for railroad managers, superintendents, master mechanics, engineers, architects, and students. Nueva York: J. Wiley \& sons.

Borie, Alain, Micheloni, Pierre y Pinon, Pierre. 1978. Forma y deformación. Barcelona: Reverté.

Bucci, Federico. 2002. Albert Kahn: Architect of Ford. Nueva York: Princeton Architectural Press.

Condit, Carl W. American Building Art. Vol 1. The Nineteenth Century. 1960. Nueva York. Oxford University Press.

Christen, Barbara S y Flanders, Steven. 2001. Cass Gilbert, Life and Work: Architect of the Public Domain. Nueva York. W.W. Norton And Company.

C. W. Hunt Company. 1893. Coal Handling machinery. Designed and manufactured by the C. $H$. Hunt Company. Nueva York. C. H. Hunt Company.

De la Torre Diaz, Francisco Javier. 2001. El modelo de diálogo intercultural de Alasdair MacIntyre. Madrid: Dykinson-Universidad San Pablo CEU.

Ferry, W Hawkins. 1970. The legacy of Albert Kahn. Detroit: Wayne State University Press.

Foster, Wolcott C. 1908. A treatise on wooden trestle bridges according to the present practice on Ame rican railroads. Nueva York: J. Wiley \& sons.

Giedion, Sigfried. 1970. Mechanization Takes Command: A Contribution to Anonymous History. New York: Oxford University Press.

Hildebrand, Grant. 1974. Designing for industry: the architecture of Albert Kahn. Cambridge: The MIT Press.

Hounshell, David A. 1984. From the American System to Mass Production. Baltimore: The Johns Hopkins University Press.

Hugel, G. C. 1938. Historical Sketch of Dearborn Station. Railway \& Locomotive Historical Society Bulletin, No. 47. 46, 95

Hyde, Charles K. 1996. Assembly-Line Architecture: Albert Kahn and the Evolution of the U.S. Auto Factory, 1905-1940. IA, The Journal of the Society for Industrial Archeology. V 22, N 2.

Kemp, Emory L. 2005. American Bridge Patents: The First Century, 1790-1890. Morgantown: West Virginia University Press.

Le Corbusier. 2006. Hacia una arquitectura. Barcelona: Ediciones Apostrofe. 
Lee, Charles E. 1943. The evolution of railways. Londres: The Railway Gazette.

Macintyre, Alasdair. 1981. After virtue. A Study in Moral Theory. Notre Dame: University of Notre Dame Press.

Macintyre, Alasdair. 1988. Whose Justice? Wich Rationality?. Notre Dame: University of Notre Dame Press.

Marquis, Albert Nelson. 1914. The Book of Detroiters. A Biographical Dictionary of Leading Living Men of the City of Detroit. Chicago: A. N. Marquis \& Company.

Martí Arís, Carlos. 1993. Las variaciones de la identidad. Barcelona: Ediciones del Serbal-C.O.A.C.

Meeks, Carrol L.V. 1995. The railroad station. An architectural history. Nueva York: Dover Publications.

Middleton, William D. 1999. Landmarks on the Iron Road. Two Centuries of North American Railroad Engineering. Bloomington: Indiana University Press.

Nelson, George. 1939. Industrial architecture of Albert Kahn inc. Nueva York: Architectural Book Publishing Company.

Nye, David E. 2013. America's assembly line. Cambridge: MIT Press.

Schneider, Charles Conrad. 1885. The cantilever bridge at Niagara Falls. With discussion. Buffalo: American Society of Civil Engineers.

Simondon, Gilbert. 2008. El modo de existencia de los objetos técnicos. 1956. Buenos Aires: Editorial Prometeo.

VV. AA. 1889. The American railway; its construction, development, management, and appliances. Nueva York: C. Scribner's sons.

VV. AA. 1972. Albert Kahn: Architect abroad. Exhibition organized by the graduate seminar in museum practice. Catalogue. Ann Arbor: The University of Michigan Museum of Art.

Fecha final recepción artículos: 24/04/2016

Fecha aceptación:

21/06/2016

Articulo sometido a revisión por dos revisores independientes por el método doble ciego. 